\title{
Regional Climate Change in Tropical and Northern Africa due to Greenhouse Forcing and Land Use Changes
}

\author{
Heiko Paeth \\ Geographical Institute, University of Würzburg, Würzburg, Germany \\ KAI BORN \\ Institute for Geophysics and Meteorology, University of Köln, Köln, Germany \\ ROBIN GIRMES \\ Meteorological Institute, University of Bonn, Bonn, Germany \\ RAlf Podzun ANd Daniela JACOB \\ Max-Planck-Institute for Meteorology, Hamburg, Germany
}

(Manuscript received 20 December 2007, in final form 23 June 2008)

\begin{abstract}
Human activity is supposed to affect the earth's climate mainly via two processes: the emission of greenhouse gases and aerosols and the alteration of land cover. While the former process is well established in state-of-the-art climate model simulations, less attention has been paid to the latter. However, the low latitudes appear to be particularly sensitive to land use changes, especially in tropical Africa where frequent drought episodes were observed during recent decades. Here several ensembles of long-term transient climate change experiments are presented with a regional climate model to estimate the future pathway of African climate under fairly realistic forcing conditions. Therefore, the simulations are forced with increasing greenhouse gas concentrations as well as land use changes until 2050. Three different scenarios are prescribed in order to assess the range of options inferred from global political, social, and economical development. The authors find a prominent surface heating and a weakening of the hydrological cycle over most of tropical Africa, resulting in enhanced heat stress and extended dry spells. In contrast, the large-scale atmospheric circulation in upper levels is less affected, pointing to a primarily local effect of land degradation on near-surface climate. In the model study, it turns out that land use changes are primarily responsible for the simulated climate response. In general, simulated climate changes are not concealed by internal variability. Thus, the effect of land use changes has to be accounted for when developing more realistic scenarios for future African climate.
\end{abstract}

\section{Introduction}

The welfare of human societies and ecosystems in tropical Africa has proven to be very sensitive to climate fluctuations (de Wit and Stankiewicz 2006; Challinor et al. 2007). Since the late 1960s, prominent drought conditions have prevailed over most of subSaharan Africa and led to substantial economic loss and

Corresponding author address: Heiko Paeth, Geographical Institute, University of Würzburg, Am Hubland, Würzburg 97074, Germany.

E-mail: heiko.paeth@uni-wuerzburg.de large-scale migration processes (Findley 1994; Benson and Clay 1998; Nicholson 2001). As a consequence, fairly realistic scenarios for future African climate are needed as a scientific basis for political measures and planning in terms of food security, water supply, and health. Such climate projections can only be realized with climate models at a spatial resolution and temporal extent that meet the complex scale interactions in the climate system as well as the requirements by decision makers at the regional to national scale (Jenkins et al. 2002).

The scientific consensus says that long-term climate trends in tropical Africa may be primarily initiated by 
changes in the tropical oceans (Paeth and Hense 2004; $\mathrm{Lu}$ and Delworth 2005; Hoerling et al. 2006) and secondarily enhanced by feedbacks with the land surface conditions, that is, vegetation cover, albedo, and soil moisture (Douville et al. 2000; Feddema and Freire 2001; Knorr and Schnitzler 2006). However, most investigations of future African climate change have been focused on the impact of increasing greenhouse gas (GHG) concentrations, which usually satisfy the effect of warmer tropical oceans but neglect the role of land cover changes (Pielke et al. 2002). Several of the GHGinduced experiments from global climate models predict a northward extension of moisture advection into the Sahel zone and more humid conditions (Kamga et al. 2005; Hoerling et al. 2006), but still with little agreement between different climate models (Hulme et al. 2001; Maynard and Royer 2004; Coppola and Giorgi 2005; Cook and Vizy 2006; Paeth et al. 2008). The most recent Intergovernmental Panel on Climate Change (IPCC) report does not shed more light on the aspect of African climate change (Solomon et al. 2007): various figures in chapters 10 and 11, which are based on results from different climate models, highlight the model uncertainty, particularly over tropical and northern Africa (e.g., Solomon et al. 2007, Fig. 11.3). The inhomogeneity of different model projections is also reflected by the low values of the regional climate change index, in Giorgi (2006), based on regional temperature and precipitation changes in the IPCC multimodel ensemble framework. This model discrepancy may be interpreted as either the result of uncertain model parameters, which specifically impact the simulation of African climate, or the fact that increasing greenhouse gas concentrations may not play a major role in future African climate. Indeed, several plausible mechanisms of how global warming may affect African rainfall are conceivable, some of them leading to more humid, others to more arid, conditions in sub-Saharan Africa (Hulme et al. 2001; Paeth and Stuck 2004; Kamga et al. 2005; Cook and Vizy 2006; Hoerling et al. 2006; Paeth and Hense 2006). Hence, the question arises whether the classical procedure of the IPCC, namely, the assessment of anthropogenic climate change by prescribing rising GHG and aerosol concentrations, is sufficient for the prediction of future African climate (Pielke et al. 2002). Another important factor for climate change, particularly in the low latitudes, may be the changing land cover in the form of land use changes owing to human activity like agriculture, shifting cultivation, pasture, urbanization, and transport infrastructure (Feddema et al. 2005). On the other hand, land cover changes as a natural response to climate change, like, for example, albedo changes in high latitudes, may be crucial in the extratropical regions. Regional studies for the United States, China, and Europe have shown that urbanization, land use changes, and vegetation loss may enhance the amplitude of near-surface warming considerably by up to a factor of 2 (Zhao and Pitman 2002). In tropical Africa, however, the effect on the hydrological cycle would be more relevant.

Several authors have suggested that the prevailing droughts during the second half of the twentieth century were at least partly caused by land cover changes in tropical and subtropical Africa (Zeng and Neelin 2000; Pielke 2001; Semazzi and Song 2001; Zeng et al. 2002). Texier et al. (2000) have shown that the African monsoon system is much more sensitive to lowfrequency changes in vegetation cover than, for instance, the South Asian monsoon. Especially, Sahelian rainfall appears to be closely tied to vegetation cover (Charney 1975; Eltahir and Bras 1993; Eltahir 1996; Wang and Eltahir 2000; Wang et al. 2004). On the observational side, satellite data reveal a clear relationship between the occurrence of drought years in the Sahel zone and vegetation (Eklundh and Olsson 2003; Lotsch et al. 2003). So far, the potential future effect of deforestation and reduced vegetation cover in Africa has mainly been studied with coarse-grid global climate models in the form of time slice experiments and idealized forcing (Taylor et al. 2002; Maynard and Royer 2004; Feddema et al. 2005; Lamptey et al. 2005; Werth and Avissar 2005). In general, reduced vegetation results in a weakening of the hydrological cycle and an enhanced near-surface warming in sub-Saharan Africa (Semazzi and Song 2001; Paeth 2004; Lamptey et al. 2005; Paeth and Thamm 2007). All of these experiments represent sensitivity studies, which are not appropriate to trace a realistic pathway of future African climate. In addition, they mostly rely on one single model simulation (Feddema et al. 2005) and, hence, do not account for uncertainties arising from the mainly unknown initial conditions.

In this paper we present ensembles of transient simulations with the regional climate model REMO (Jacob et al. 2001, 2007) in $0.5^{\circ}$ resolution over tropical and northern Africa (Paeth et al. 2005), prescribing enhanced greenhouse conditions as well as land use changes until 2050. The objective is to assess future African climate change under fairly realistic forcing conditions and with high regional detail. We have considered three scenarios of GHG emissions and land cover changes in order to evaluate the range of options given by different achievements in mitigation policy and to quantify the relative contribution of land degradation. Note that we are not able to assess the uncertainty arising from different climate models in Africa, 
simply because computing resources are still not yet available to realize long-term multimodel ensembles with high-resolution regional climate models. REMO participated in the Prediction of Regional Scenarios and Uncertainties for Defining European Climate Change Risks and Effects (PRUDENCE), an intercomparison project of regional climate models for present-day climate in Europe (Jacob et al. 2007), and the longer-term perspective is to produce transient multimodel ensembles with regional climate models in the Ensemble Based Predictions of Climate Changes and Their Impacts (ENSEMBLES) project (information online at http://ensembles-eu.metoffice.com). Nevertheless, previous studies with the REMO model have highlighted the good performance of the model in terms of the basic features of African climate, including the complex midtropospheric jet and wave dynamics and the seasonality of climate in the monsoon regions (Paeth et al. 2005).

The characteristics of REMO and the experimental design are described in the following sections. Section 3 is dedicated to the model validation. Changes in the mean climate features of Africa are presented in section 4 , while climate extremes are dealt with in section 5. Section 6 portrays a decomposition of external and internal contributions to total variability. The results are summarized and discussed in section 7 .

\section{Model and scenario description}

REMO is a hydrostatic limited-area model that has been designed for applications at the synoptic scale (Jacob et al. 2001, 2007). It is based on primitive equations with temperature, horizontal wind components, surface pressure, water vapor, and cloud water content as prognostic variables. Physical parameterization are taken from the global ECHAM4 model, moist convection is governed by the Tiedtke mass flux scheme. Land surface processes are simulated by a five-layer soil model. In the present case, REMO is centered over tropical and northern Africa and comprises the sector $15^{\circ} \mathrm{S}-$ $45^{\circ} \mathrm{N}, 30^{\circ} \mathrm{W}-60^{\circ} \mathrm{E}$. This quite large model domain has been chosen in order to allow for the development of self-contained synoptic weather systems in REMO independent of the lateral boundary forcing, to reduce the effect of orography at the lateral boundaries, and to keep tropical and northern Africa off the spurious lateral boundary effects. In contrast, more regional details of the lower oceanic forcing cannot be assessed because the SST patterns are taken from the coupled global climate model ECHAM5/Max Planck Institute Ocean Model (MPI-OM). The horizontal resolution is $0.5^{\circ} ; 20$ hybrid atmospheric levels are differentiated. To dimin- ish lateral boundary effects six gridpoint rows are removed from the maps shown below and are not interpreted. We use REMO in version 5.7 with an improved land surface scheme and fractional land-sea mask. For the control experiments, land surface parameters like orography, vegetation cover, albedo, and roughness length are taken from the U.S. Geological Survey (USGS) Global 30 Arc-Second Elevation Data Set (GTOPO30) and NOAA) datasets that are representative for the late twentieth century (Hagemann et al. 1999). For the scenario runs, these data serve as a reference basis for the imposed twenty-first-century land cover changes (see below).

In this study, all REMO simulations are driven by recent ECHAM5/MPI-OM global coupled climate model simulations, which themselves are forced with enhanced greenhouse and sulfate aerosol (only direct effect) conditions and participate in the international modeling approach for the Fourth Assessment Report of the IPCC (Roeckner et al. 2003). Compared with previous studies, the simulations with REMO have the following important advantages: 1) A regional climate model is used with a six times higher resolution than most present-day global simulations. 2) Spatially detailed patterns of future land use changes are prescribed in addition to increasing GHG concentrations (see below). 3) Transient forcing is realized, extending from 1960 to 2050. 4) During the 1960-2000 period increasing GHGs and constant land cover from the early 1990s are prescribed; from 2001 to 2050 increasing GHGs and changing land cover according to a businessas-usual and a mitigation scenario from the IPCC Special Report on Emission Scenarios (SRES) A1B and B1 scenarios (Nakicenovic and Swart 2000) are considered, referred to as $\mathrm{A} 1 \mathrm{~B}(\mathrm{all})$ and $\mathrm{B} 1$ (all) hereafter. To quantify the relative contribution of the land use changes to total climate change in Africa additional simulations are realized with REMO using the A1B emission scenario between 2001 and 2050, but no land use changes, referred to as $\mathrm{A} 1 \mathrm{~B}$ (ghg). Assuming that the different scenarios arise from different political strategies, comparison of the $\mathrm{A} 1 \mathrm{~B}(\mathrm{all}), \mathrm{A} 1 \mathrm{~B}(\mathrm{ghg})$, and $\mathrm{B} 1$ (all) ensemble predictions from REMO may provide a first glance on the particular role of landscape protection in Africa. In this context, the conservation of rain forests in tropical Africa has a double benefit by mitigating land degradation as well as greenhouse gas emissions. 5) Each scenario and the twentieth-century simulations are represented by three ensemble members in order to obtain a measure of uncertainty.

One challenging task was to produce high-resolution patterns of future land cover change until 2050. For our regional climate model approach, we decided not to use 

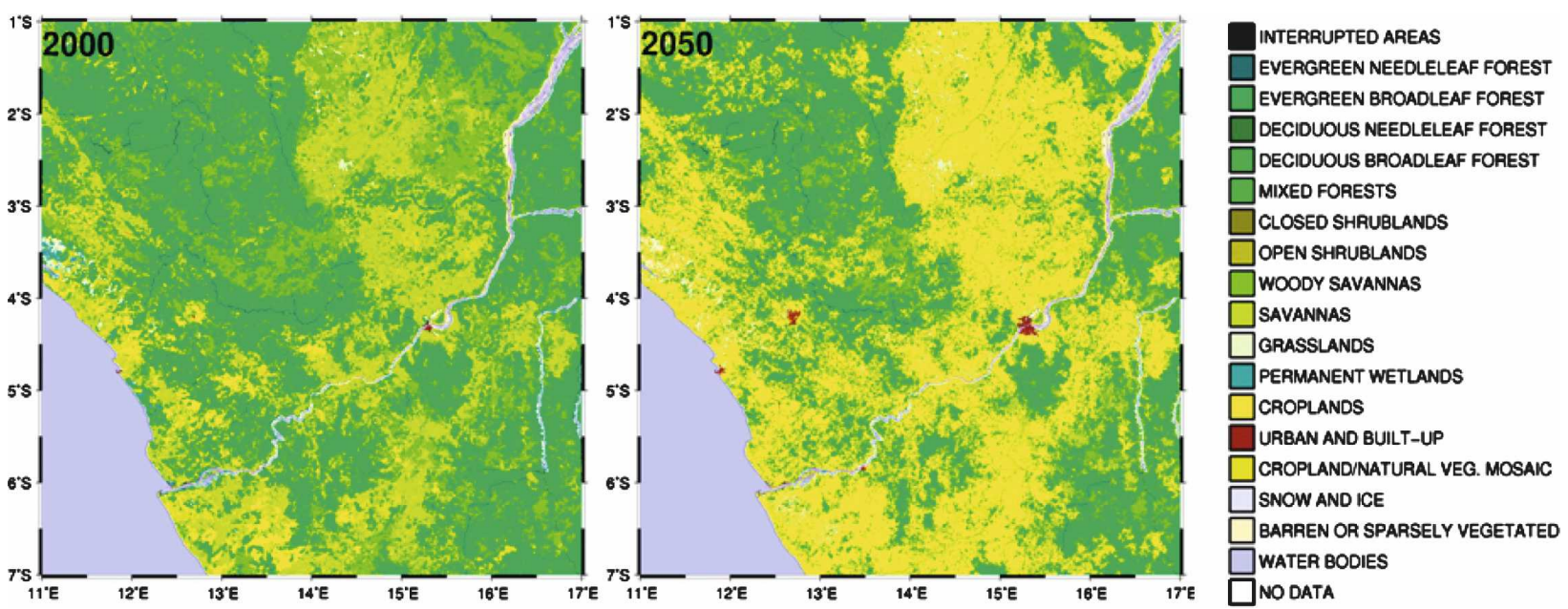

FIG. 1. Simulated land cover on the basis of the $1 / 120^{\circ} \times 1 / 120^{\circ}$ land cover pixels from the USGS GLCC dataset in the lower Congo region with a general transformation of evergreen forests to cropland and an extension of urban areas between (left) 2000 and (right) 2050.

the land cover projections as in Feddema et al. (2005), which are based on an environmental model at relatively rough resolution reacting on climate change. Instead, we have developed a stochastic land use change model based on assumptions for future population growth and urbanization in Africa. Our model is more specialized on the process of land degradation in tropical Africa with the characteristic scattered pattern of deforestation and uncontrolled settlement. The land cover projections for REMO comprise two steps.

First, a stochastic land use change model is applied to the USGS Global Land Cover Characterization (GLCC) land cover classification in $1 \times 1 \mathrm{~km}^{2}$ resolution (available online at http://edcsns17.cr.usgs.gov/ glcc/globalpubs.html). This resolution is appropriate to account for the observed spatially heterogeneous process of agricultural expansion and shifting cultivation as inferred from satellite measurements (Oertel et al. 2004; Thamm et al. 2005). The degree of land cover change is related to estimates on population growth in Africa according to the United Nations report (UN 2006). Assuming a growth rate of $2 \% \mathrm{yr}^{-1}$ for the $\mathrm{A} 1 \mathrm{~B}$ scenario, land use changes are mainly prevailing in the neighborhood of cities as well as currently existing agricultural areas and traffic axes. The stochastic model implies that the precise pattern of the land cover change is random under some fairly realistic constraints: 1 ) The projected demographic and economic development of UN (2006) is considered. 2) It is assured that in the regional mean over tropical Africa the simulated deforestation rate matches the estimate by the FAO (2006) exactly, which amounts to $30 \%$ until 2050 in entire tropical Africa, concerning all forest categories of the
USGS GLCC land cover classification listed in Fig. 1. 3) Land cover grid boxes at the $1-\mathrm{km}$ resolution can only be affected if a neighboring grid box has been anthropogenically manipulated before. To illustrate this process Fig. 1 shows the transformation of evergreen forests and savannas to cropland and the extension of urban areas in an example region in western Congo. It is obvious that this transformation takes place mainly along the boundaries of dense woodlands, whereas in the central part of the rain forests the natural vegetation is retained. These constraints ensure that the overall picture of the land cover changes reveals a plausible structure, although the change in each individual grid box is still random. In other regions, like the southern Sahel zone, the desertification process is simulated as well with grassland being entirely transformed to bare soil due to overgrazing and inappropriate agriculture. The extrapolation of the observed desertification process until 2050 is also based on estimates of the FAO (2006) and blended with demographic estimates from UN (2006). Given the dramatic deforestation rates in the past (e.g., Thamm et al. 2005), a future reduction of $30 \%$ until 2050 is not necessarily the worst case but a reasonable assumption of the FAO (2006). However, note that the scenario setup used here does not allow for fully interactive vegetation feedbacks, that is, the vegetation cover reacting to the simulated climate changes. On the one hand, such a feedback could strengthen the land cover changes because of reduced rainfall. On the other hand, recovering vegetation after abundant rain events could partly compensate the imposed land cover changes.

Second, the high-resolution pattern of scattered/ 
heterogeneous land cover changes at $1 \times 1 \mathrm{~km}^{2}$ resolution is adjusted to the scale of REMO, which is $0.5^{\circ}$, and transformed to the relevant land surface parameters. This is done with the improved preprocessor algorithm from Hagemann (2002). In total, five surface parameters are required in REMO to parameterize the relevant land processes: vegetation ratio, forest fraction, leaf area index, roughness length, and surface albedo. Note that stomatal resistance is not taken into account. All of these land surface conditions are modified consistently in order to account for the full range of atmospheric processes affected by changes in land cover. Maynard and Royer (2004) have shown that all surface parameters are equally important in simulating the effect of land degradation. The land use scenarios are transient throughout the $2000-50$ period and are superimposed on the seasonal cycle of vegetation in Africa. Figure 2 illustrates the present-day pattern of forest and vegetation cover over Africa and the imposed changes until 2050 under the A1B and B1 scenarios. Both scenarios do not lead to considerably different estimates on future land use changes because the population growth rate is identical under $\mathrm{A} 1 \mathrm{~B}$ and $\mathrm{B} 1$ (Nakicenovic and Swart 2000). Nonetheless, it is assumed that under B1 technological progress may result in more efficient agriculture and, hence, less agricultural expansion. The changes in forest fraction are strongest along the boundaries of dense woodland areas in the Congo Basin and in western tropical Africa. The reduction in total vegetation cover reflects the process of desertification in the southern Sahel zone. Note that the spatial mean of the forest changes under the A1B scenario (middle left panel) is identical to the estimate of the FAO (2006), which is $-30 \%$ until 2050 for entire Africa. Under the A1B(all) scenario the associated albedo changes between 2000 and 2050 are on the order of $5 \%-10 \%$ where forests are replaced by grassland and agricultural area and $10 \%-15 \%$ where desertification takes place (not shown).

Of course, we cannot ensure that land use in the future will exactly develop as indicated in Fig. 1. However, for the scale of our regional model we suppose that the patterns in Fig. 2 are reasonable. In addition, we do not claim to produce exact forecasts, but projections under reasonable assumptions for future human activity. Note that this is a model-into-model approach, whicht depends on the specific physical parameterizations in the ECHAM5/MPI-OM and REMO climate models. Thus, we cannot account for model uncertainties in the multimodel fashion of the IPCC. Furthermore, we cannot exclude that REMO may suffer from a wrong response of the ECHAM5/MPI-OM global climate model to increasing greenhouse gas and sulfate aerosol concentrations. Anyway, we find a prominent spatial coherence between the ECHAM5/MPI-OM ensemble-mean pattern of precipitation changes over Africa and the multimodel ensemble-mean pattern in the IPCC Fourth Assessment Report (Solomon et al. 2007, cf. Fig. 11.2, p. 869) which, however, is subject to large intermodel uncertainty. Another restriction of our model projections is that the various effects of changing atmospheric aerosol concentrations (cf. Paeth and Feichter 2006) are not accounted for by REMO because the integration of a complex aerosol model, including aerosols from biomass and fossil fuel burning and their interaction with cloud microphysics, was still too expensive from a computational point of view. In the following, it will be demonstrated to which extent African climate is sensitive to these changes in surface parameters although the overall deforestation is only about $30 \%$.

\section{Model validation}

In a detailed validation study Paeth et al. (2005) have shown that REMO is able to simulate all basic features of African climate including the regional patterns of near-surface climate, the monsoon circulation, and even mesoscale phenomena, like the twofold intertropical convergence zone in boreal summer and African easterly waves. These findings referred to a long-term integration with REMO driven by ECMWF (re) analyses, which also reproduced the observed interannual rainfall variability and interdecadal drought tendency in sub-Saharan Africa during the second half of the twentieth century. In the present case, we consider REMO simulations driven by the coupled global climate model ECHAM5/MPI-OM for 1960-2050. Thus, potential model errors in ECHAM5 and REMO are superimposed. Therefore, we first compare the REMO data during the 1960-2000 control period with available observational data in order to demonstrate the ability, and some deficiencies, of the model-into-model approach.

Figure 3 illustrates the simulated and observed climatological patterns of annual precipitation and nearsurface temperature. At first sight, REMO is able to reproduce the observed patterns in an excellent way (cf. Saha and Saha 2001). Note that no postprocessing (model output statistics) of the model data is done. The distribution of rainfall amount is very close to the Climatic Research Unit (CRU) dataset. The latter has been produced by means of statistical interpolation of all available station data over land since the beginning of the twentieth century to a gridded dataset at $0.5^{\circ}$ resolution (New et al. 2000). Note that the CRU dataset is deficient in regions with low data coverage, like parts 

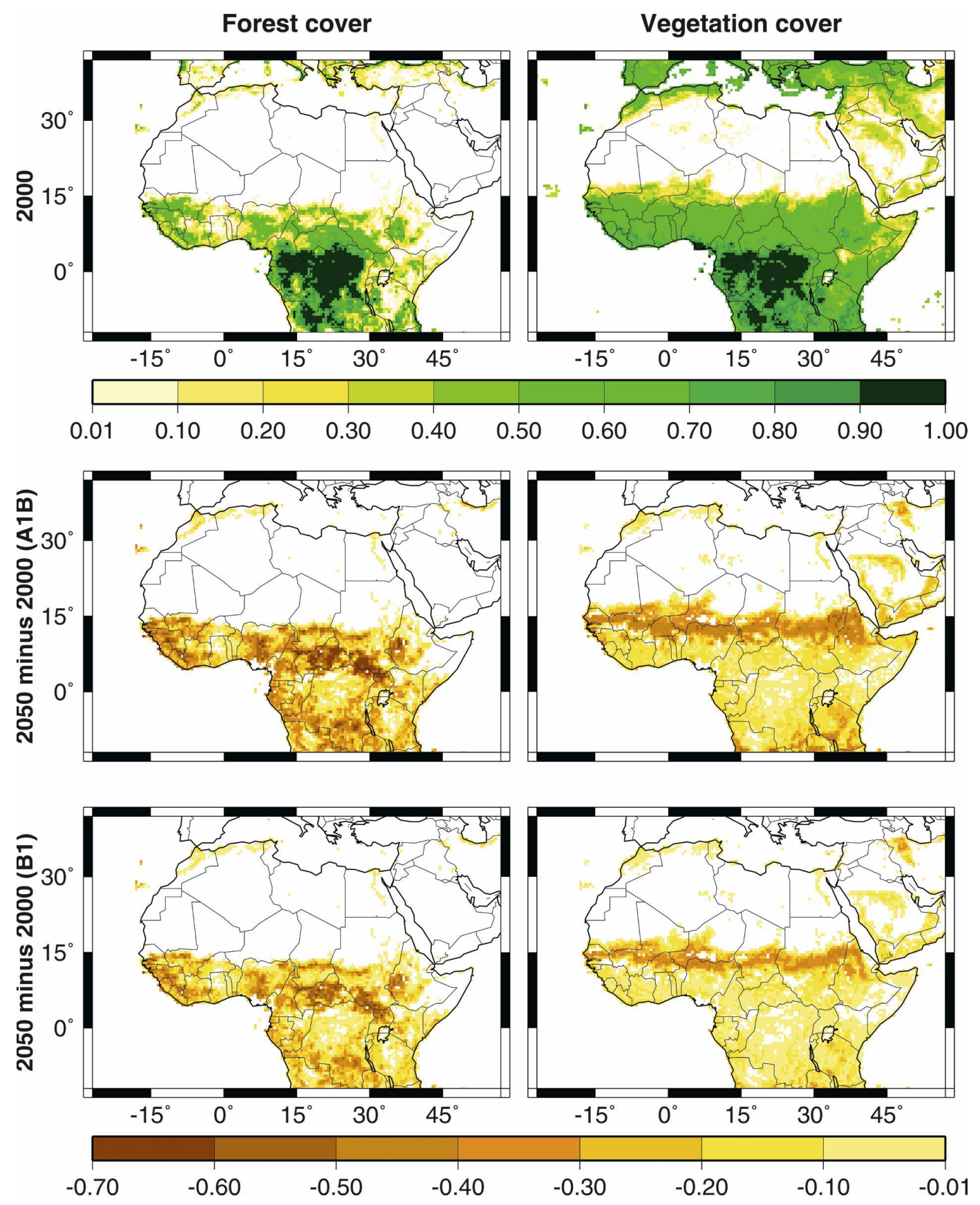

FIG. 2. Present-day forest fraction and vegetation fraction and prescribed land cover change scenarios (unit $=$ 1): (top) present-day conditions, and changes in forest and vegetation fraction until 2050 under the (middle) A1B and (bottom) B1 scenario.

of Africa-a problem which holds for all available gridded rainfall datasets. In particular, the meridional gradient of annual precipitation over sub-Saharan West Africa is realistically simulated. However, the model has a wet bias in the southern part of the Congo Basin, which is not in the focus of this study. The simulated temperature pattern looks reasonable, as well, except for a warm bias over the eastern Arabian Peninsula, which may arise from data gaps in the CRU dataset. In particular, the orographic effect of the East African highlands is close to the CRU data. It should be noted that the absolute temperature values in both datasets, REMO and CRU, may have a systematic warm bias with respect to station data due to the dynamical and 

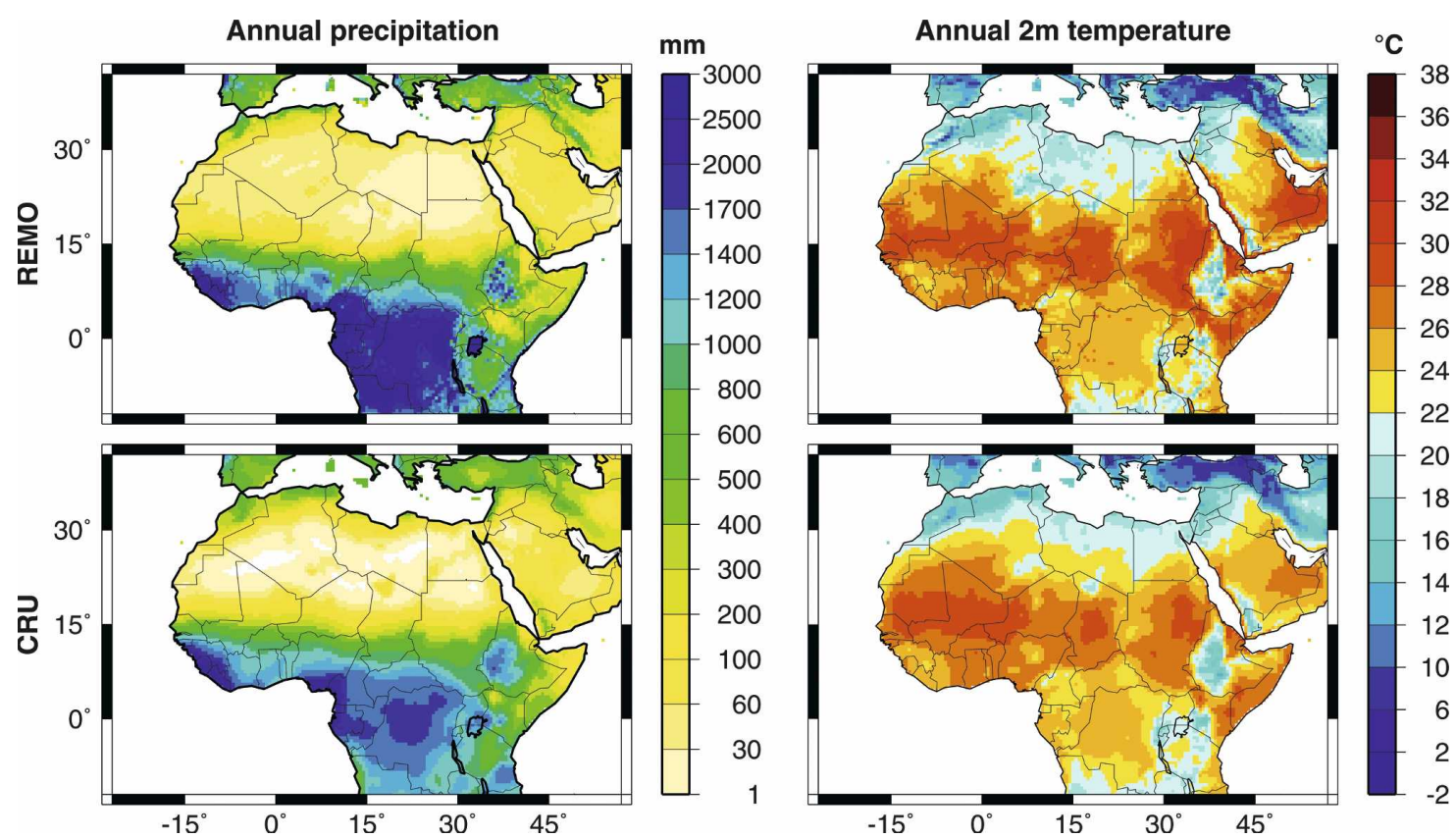

FIG. 3. Simulated and observed climatology of annual precipitation in mm and near-surface temperature $\left({ }^{\circ} \mathrm{C}\right)$ during the 1960-98 overlapping period of REMO (three-member ensemble mean) and CRU.

statistical interpolation, respectively. In general, the simulated patterns are characterized by more regional detail than the observed ones, which is an effect of the dynamical versus statistical interpolation in REMO and CRU.

Figure 4 refers to the simulated and observed seasonal cycle and interannual variability. The mean seasonal cycle of precipitation in the West African monsoon region is very well reproduced with a slightly overestimated amplitude: the model is too wet in August and September and too dry in December and January. In terms of near-surface temperature, REMO overestimates the seasonal cycle, more noticeably, by up to $2^{\circ} \mathrm{C}$ in December and January. This effect is probably related to cloudiness, which is difficult to be validated since 1960. In addition, it is unclear to what extent the CRU data may misjudge the seasonal cycle of temperature in sub-Saharan Africa. In contrast to rain gauge stations, the density of temperature measurements is quite low over Africa. The bottom panels in Fig. 4 display the year-to-year variability of monthly precipitation and temperature compared between REMO and CRU. While the interannual temperature variability is well reproduced, except during boreal winter, the model clearly underestimates the year-to-year fluctuations of rainfall during the summer monsoon season. This discrepancy can be explained by the fact that the REMO simulations are not driven by observed sea surface temperatures but simulated SSTs from a coupled global climate model with T63 resolution (ECHAM5/ MPI-OM) and that the feedbacks of atmospheric processes on vegetation cover are not taken into account. Many authors have suggested that both factors have led to the prominent drought tendency since the 1960s (Douville et al. 2000; Feddema and Freire 2001; Nicholson 2001; Knorr and Schnitzler 2006). This interdecadal rainfall trend dominates the interannual variability in the CRU dataset but is not simulated by REMO during the 1960-2000 period because the drought signal is not contained in the coupled global climate model. When REMO is driven by observed SSTs, the interannual variability and the interdecadal trend are well reproduced (Paeth et al. 2005). In addition, when land cover changes are switched on during the 2001-50 period, interannual rainfall variability increases as well. Nonetheless, we cannot exclude the fact that our model approach underestimates the amount of internal variability and, hence, overestimates the signal-to-noise ratio. Therefore, an important challenge for future work is to implement a dynamical vegetation model in ECHAM5 and REMO (cf. Schnitzler et al. 2001). Anyway, it is likely that vegetation feedbacks at decadal time scales enhance the amplitude of the climate change signals as well. Another interpretation may be that the simulated air-sea interaction in the coupled GCM leads to a systematic underestimation of climate variability at all time scales, implying the multidecadal response to enhanced radiative forcing. 

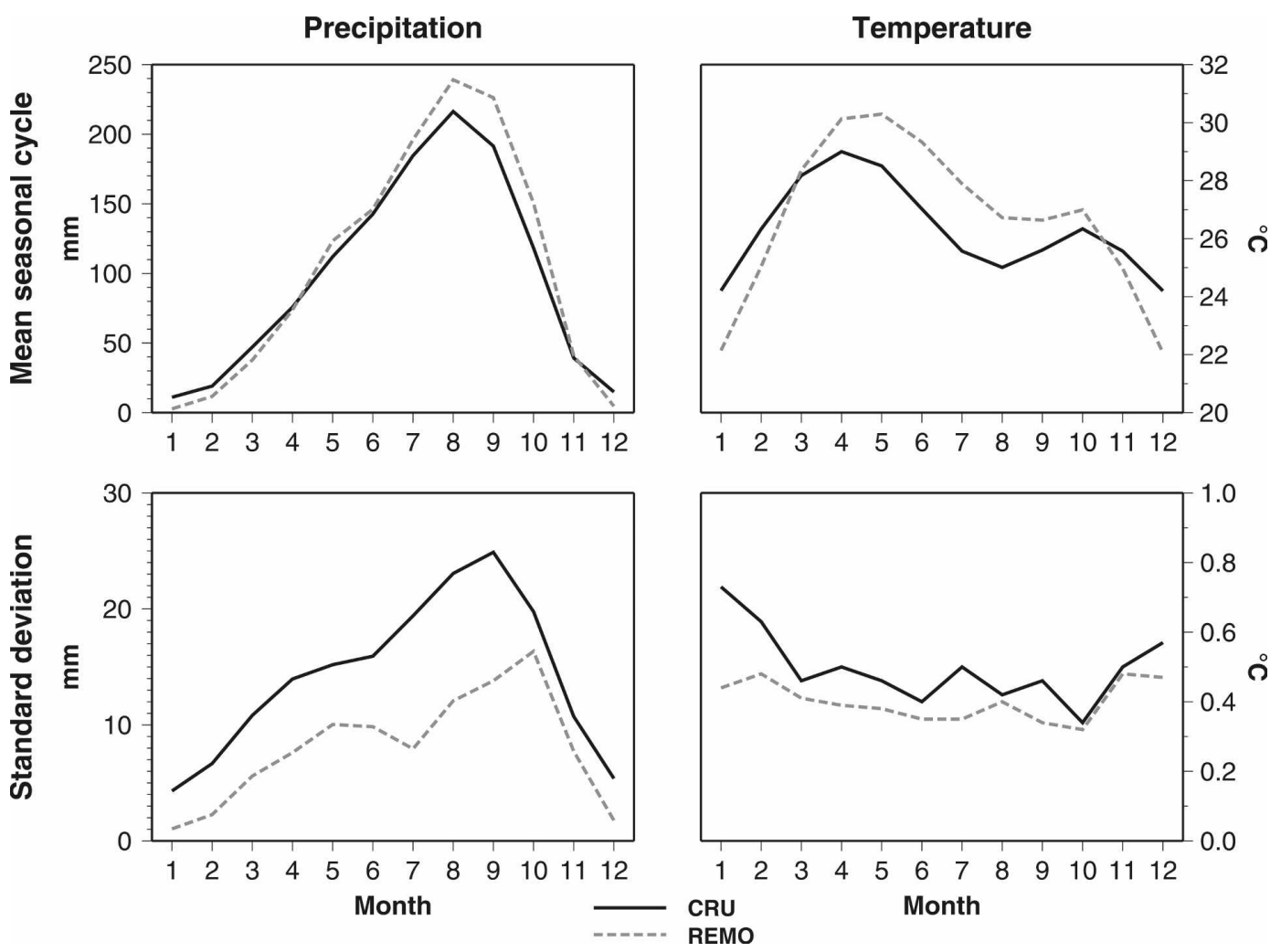

FIG. 4. Simulated ensemble-mean and observed seasonal cycle of precipitation and near-surface temperature averaged over the West African monsoon region (bordered by the western and southern Guinean Coast: $15^{\circ} \mathrm{N}$, $20^{\circ} \mathrm{E}$ ): (top) mean seasonal cycle and (bottom) standard deviation during the 1960-98 period.

\section{Changes in mean climate}

The ensemble-mean linear changes (trends for the period 2001-50 multiplied by $50 \mathrm{yr}$ ) of annual mean near-surface temperature over land are shown in Fig. 5. Each panel refers to different forcing conditions: the twentieth century with observed GHG increase and constant land cover, the $\mathrm{A} 1 \mathrm{~B}($ all) and $\mathrm{B} 1$ (all) scenarios with GHG forcing and increasing land degradation, and the A1B(ghg) scenario with GHG forcing and constant land cover. It is obvious that most of the warming takes place in the twenty-first century when land cover changes are taken into account. Under the A1B(all) scenario some parts of tropical Africa may warm by more than $3^{\circ} \mathrm{C}$ until 2050 , whereas the heating ranges between $1.5^{\circ}$ and $2.5^{\circ} \mathrm{C}$ over northern Africa and southern Europe. Under the B1(all) scenario the warming pattern is very similar but the amplitudes are generally $1^{\circ} \mathrm{C}$ lower. The strongest heating occurs in sub-Saharan Africa (although the same GHG increase is imposed all over the model domain). One explanation for this result may be that land cover changes play a major role in future African climate change. This explanation is supported by the trend pattern associated with the
$\mathrm{A} 1 \mathrm{~B}$ (ghg) scenario: the heating rate is much more homogeneous in space and considerably lower than in the A1B(all) ensemble. The simulated temperature changes are statistically significant at the $5 \%$ level practically over all landmasses and in all scenarios.

Figure 6 describes the linear changes in annual precipitation amount. During the twentieth century the trend pattern is quite heterogeneous, with slightly positive trends dominating in tropical Africa. However, most of the simulated changes are still consistent with internal variability. The observed drought tendency in the Sahel zone cannot be reproduced because the model is driven by SSTs from a coupled global climate model instead of using the observed SSTs (cf. Paeth and Hense 2004). In the A1B(all) ensemble the annual rainfall amount is decreasing by around $100 \mathrm{~mm}$ in the southern Sahel zone and up to $500 \mathrm{~mm}$ in the Congo Basin. The Mediterranean region is drying as well (cf. Paeth and Hense 2005). Compared with the presentday total amounts, this decrease is equivalent to $20 \%-$ $25 \%$ in most of sub-Saharan Africa. Over the Horn of Africa positive trends prevail. During the seasonal cycle, the warming signal is most pronounced during 

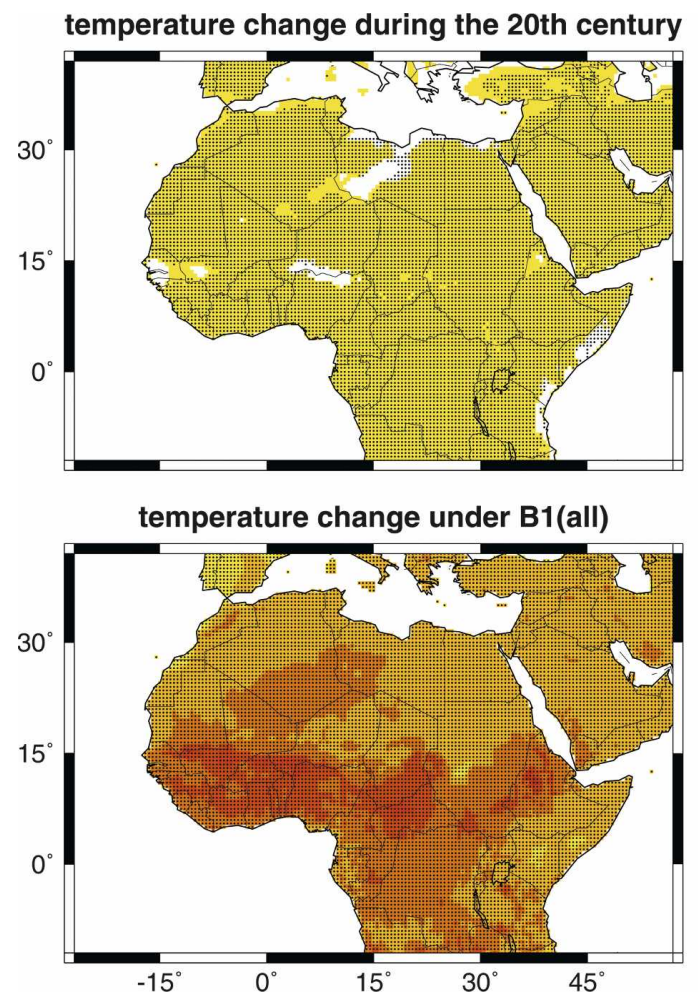

FIG. 5. Simulated ensemble-mean changes in annual near-surface temperature expressed as linear trends (multiplied by number of years) during the (top left) twentieth century (1960-2000) and the projection period (2001-50) under the three different scenarios: $\mathrm{A} 1 \mathrm{~B}($ all $)=$ strong greenhouse gas emissions and land cover changes; B1(all) = weaker greenhouse gas emissions and land cover changes; and $\mathrm{A} 1 \mathrm{~B}(\mathrm{ghg})=$ strong greenhouse gas emissions and no land cover changes. Values statistically significant at the $5 \%$ level are marked by dots.

the November-March dry season, while the strongest rainfall reduction is related to the May-September rainy season. The B1(all) scenario leads to slightly reduced negative trends but a very similar spatial pattern. Obviously, the B1(all) scenario does not noticeably mitigate the weakening of the hydrological cycle compared with the A1B(all) scenario. This is completely different for the $\mathrm{A} 1 \mathrm{~B}(\mathrm{ghg})$ scenario: The trend pattern is rather incoherent in space, of much lower amplitude, and hardly significant at the $5 \%$ level. Note that the trend patterns in Figs. 5 and 6 associated with the $\mathrm{A} 1 \mathrm{~B}(\mathrm{ghg})$ scenario are quite consistent with those in the global ECHAM5/MPI-OM model, although the global patterns reveal much less regional detail and, in addition, some regional differences in terms of precipitation (not shown).

The relative contribution of the land use changes to the simulated changes in the $\mathrm{A} 1 \mathrm{~B}($ all $)$ ensemble can be inferred from Fig. 7 (top panels). Land degradation accounts for around $35 \%$ of the warming signal in tropical Africa but is responsible for almost the entire precipitation signal, except for tropical West Africa where the greenhouse forcing contributes up to one-third to the total drying trend. The impact of land cover changes is strictly limited to tropical Africa and does not feed back to adjacent regions like the Sahara or the Mediterranean basin (cf. Werth and Avissar 2005). These results point to the additional importance and possibly direct effect of land use changes on African climate. The bottom panels in Fig. 7 further indicate that the B1(all) scenario with weaker greenhouse forcing and lower amount of land use changes according to scenario B1(all) (see section 2) leads to approximately the same surface warming as the $\mathrm{A} 1 \mathrm{~B}(\mathrm{ghg})$ scenario with stronger greenhouse forcing and constant land cover. Thus, both protection strategies attain similar mitigation effects with respect to the large heating rate under A1B(all). However, the reduction in total precipitation over tropical Africa is much more pronounced under $\mathrm{B} 1$ (all) than under A1B(ghg). Obviously, it is at least equally important to protect land cover in Africa as it is to reduce global greenhouse gas emissions in order to mitigate the drying trend in tropical Africa. Note that the comparison between trend patterns with and without land degradation still suffers from the uncertainty arising from the response of the global ECHAM5/MPI- 

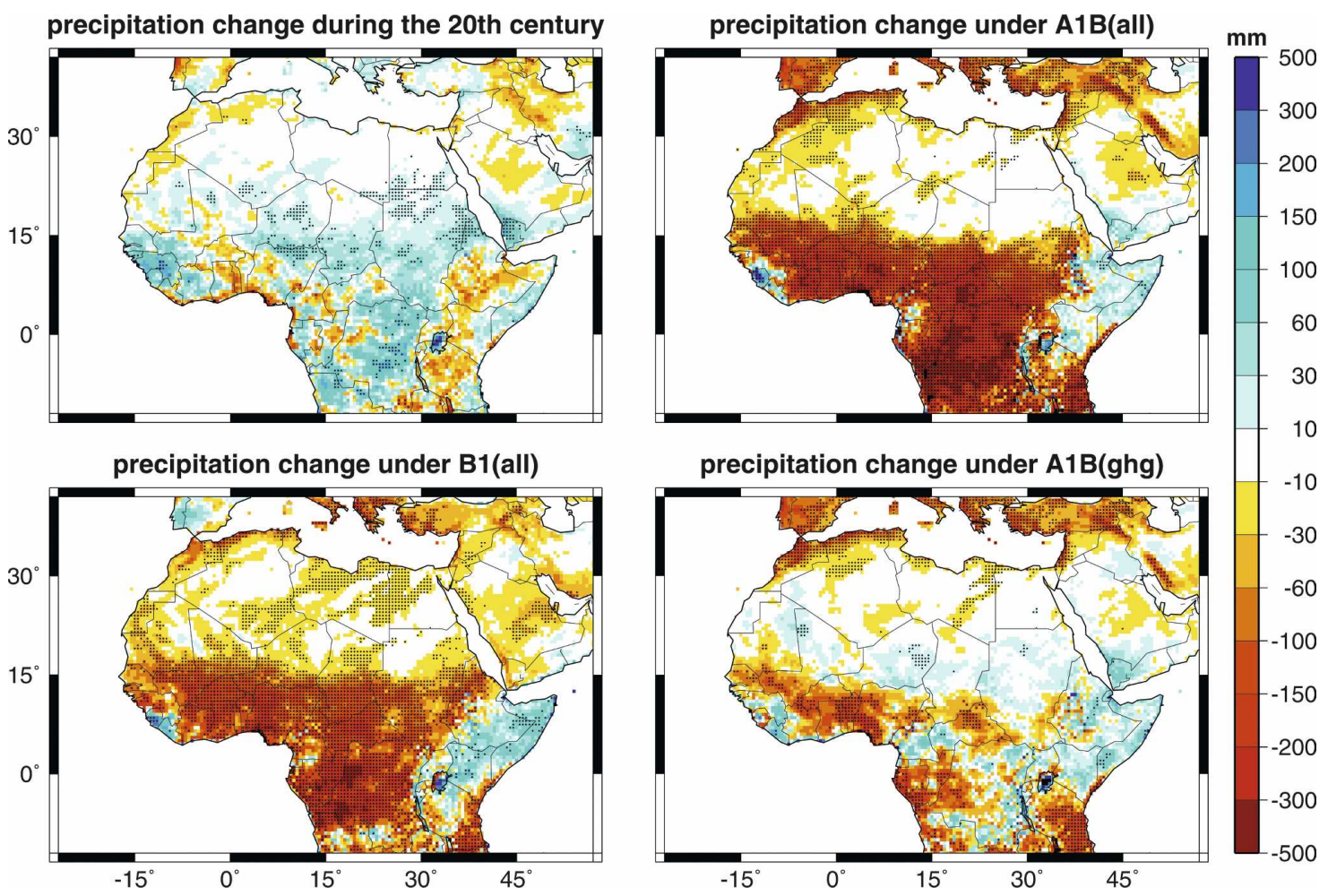

FIG. 6. As in Fig. 5 but for annual precipitation.

OM model to radiative forcing: The weak response of REMO precipitation under the $\mathrm{A} 1 \mathrm{~B}$ (ghg) scenario may also be a consequence of a deficient sensitivity of the global GCM. This uncertainty can only be evaluated on the basis of multimodel GCM-regional climate model (RCM) experiments.

The correlation coefficients in Table 1 are a measure of the local relationship between reduced vegetation cover and climate change. They represent the spatial coherency between the trend patterns of temperature and precipitation in the $\mathrm{A} 1 \mathrm{~B}$ (all) ensemble (Figs. 5 and 6 , top right) and the imposed changes in forest fraction and total vegetation cover (Fig. 2, middle). Most correlation coefficients are quite high and statistically significant at the $5 \%$ level. Note that more than 6000 grid boxes are considered in the sector from $15^{\circ} \mathrm{S}$ to $20^{\circ} \mathrm{N}$. Temperature trends are more associated with the total vegetation changes (deforestation plus degradation of grassland, etc.), whereas deforestation alone is more relevant to the rainfall changes. Almost the same results are found when the correlation analysis is applied to the $\mathrm{A} 1 \mathrm{~B}(\mathrm{all})$ minus $\mathrm{A} 1 \mathrm{~B}$ (ghg) difference patterns. In terms of precipitation, the prominent link to forest cover may reflect the importance of transpiration and interception for the local water cycle. Indeed, the strongest relationships are found in October during the late monsoon season when evapotranspiration from the vegetation cover often induces an extension of the rainy season. In terms of temperature, we do not have an obvious explanation for the stronger relationship with total vegetation cover: Actually, warming should prevail where change in the Bowen ratio is pronounced, that is, in regions with deforestation.

The local link between land degradation and climate can be explained by the following mechanism: Reduced vegetation cover leads to decreasing evapotranspiration such that more energy is available for near-surface heating. This can be expressed as a change in the Bowen ratio toward enhanced sensible and reduced latent heat fluxes (Paeth 2004; Paeth and Thamm 2007). Furthermore, reduced evapotranspiration inhibits the local water recycling, which is a key component of the hydrological cycle in the low latitudes. In some tropical continental regions the local water recycling may be responsible for an equally important portion of annual rainfall than the input from the large-scale monsoon circulation (Worden et al. 2007).

The temporal evolution of temperature and precipitation changes can be seen from Fig. 8. The time series in the right panels are built by projecting all individual model simulations onto the leading empirical orthogonal functions (EOFs) of monthly temperature and pre- 


\section{TEMPERATURE $\left({ }^{\circ} \mathrm{C}\right)$}

\section{PRECIPITATION (mm)}

A1B(all) minus A1B(ghg)
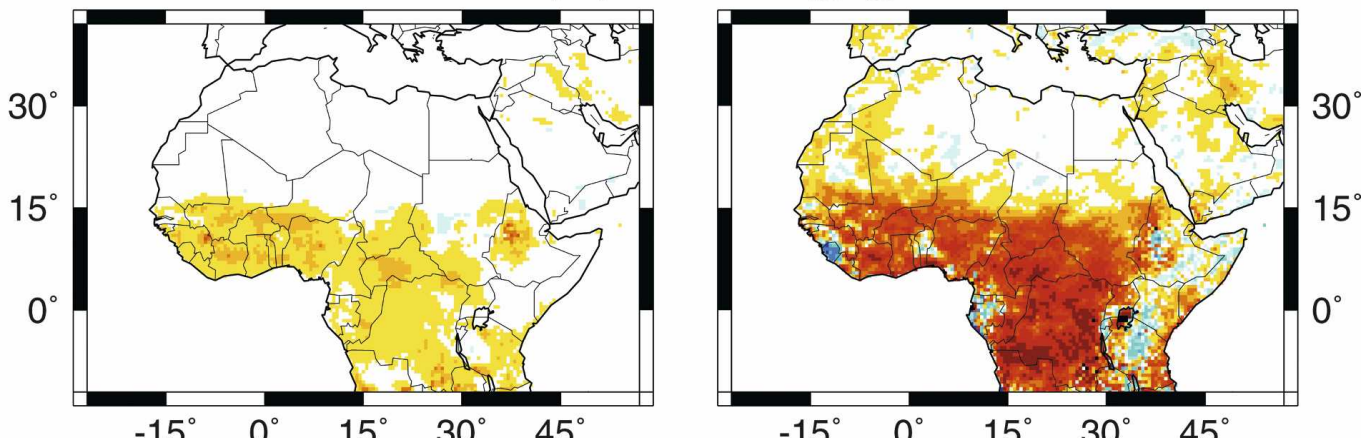

B1(all) minus A1B(ghg)
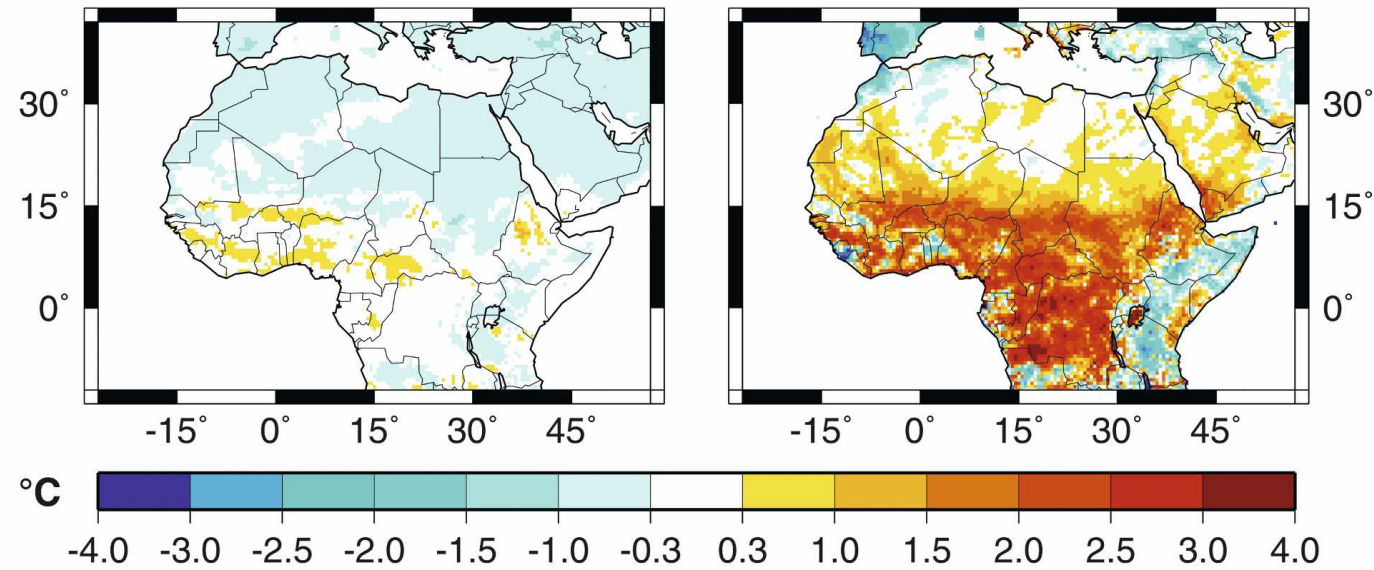

$\mathrm{mm}$

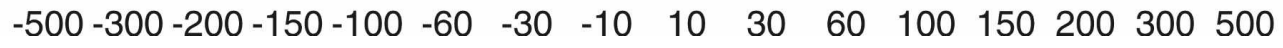

FIG. 7. Difference patterns between the climate change signals in Fig. 6 for annual precipitation and near-surface temperature: (top) A1B(all) minus $\mathrm{A} 1 \mathrm{~B}$ (ghg) reveals the relative contribution of land degradation to total climate change; (bottom) B1(all) minus $\mathrm{A} 1 \mathrm{~B}(\mathrm{ghg})$ compares the effect of a general mitigation policy in the IPCC B1 scenario with the effect of strong GHG emissions but averted land degradation.

cipitation from the A1B(all) ensemble mean (left panels). This procedure ensures that all time series have the same reference basis and can be directly compared with each other. On the other hand, we may lose some of the climate change signals in the other simulations under B1(all) and A1B(ghg) because their trend patterns may be different from the one simulated under A1B(all). Note that the mean seasonal cycle has been removed prior to computing the EOFs. The corresponding EOF patterns are very similar to the trend patterns in Figs. 5 and 6 (top right) with largest amplitude in sub-Saharan Africa. The first EOF of monthly temperature is more

TABLE 1. Spatial correlation coefficients between the trend patterns of annual precipitation and near-surface temperature under the A1B(all) scenario on the one hand (see Figs. 5 and 6) and the prescribed patterns of changing vegetation fraction and forest fraction on the other hand (see Fig. 2) for June and October over land between $15^{\circ} \mathrm{S}$ and $20^{\circ} \mathrm{N}$. Correlation coefficients statistically significant at the $5 \%$ level are marked by an asterisk.

\begin{tabular}{|c|c|c|c|c|}
\hline \multirow[b]{2}{*}{ Change } & \multicolumn{2}{|c|}{ June } & \multicolumn{2}{|c|}{ October } \\
\hline & Deforestation & Vegetation loss & Deforestation & Vegetation loss \\
\hline Temperature & $-0.22 *$ & $-0.30 *$ & $-0.14 *$ & $-0.59 *$ \\
\hline Precipitation & $+0.30^{*}$ & -0.09 & $+0.40 *$ & -0.02 \\
\hline
\end{tabular}



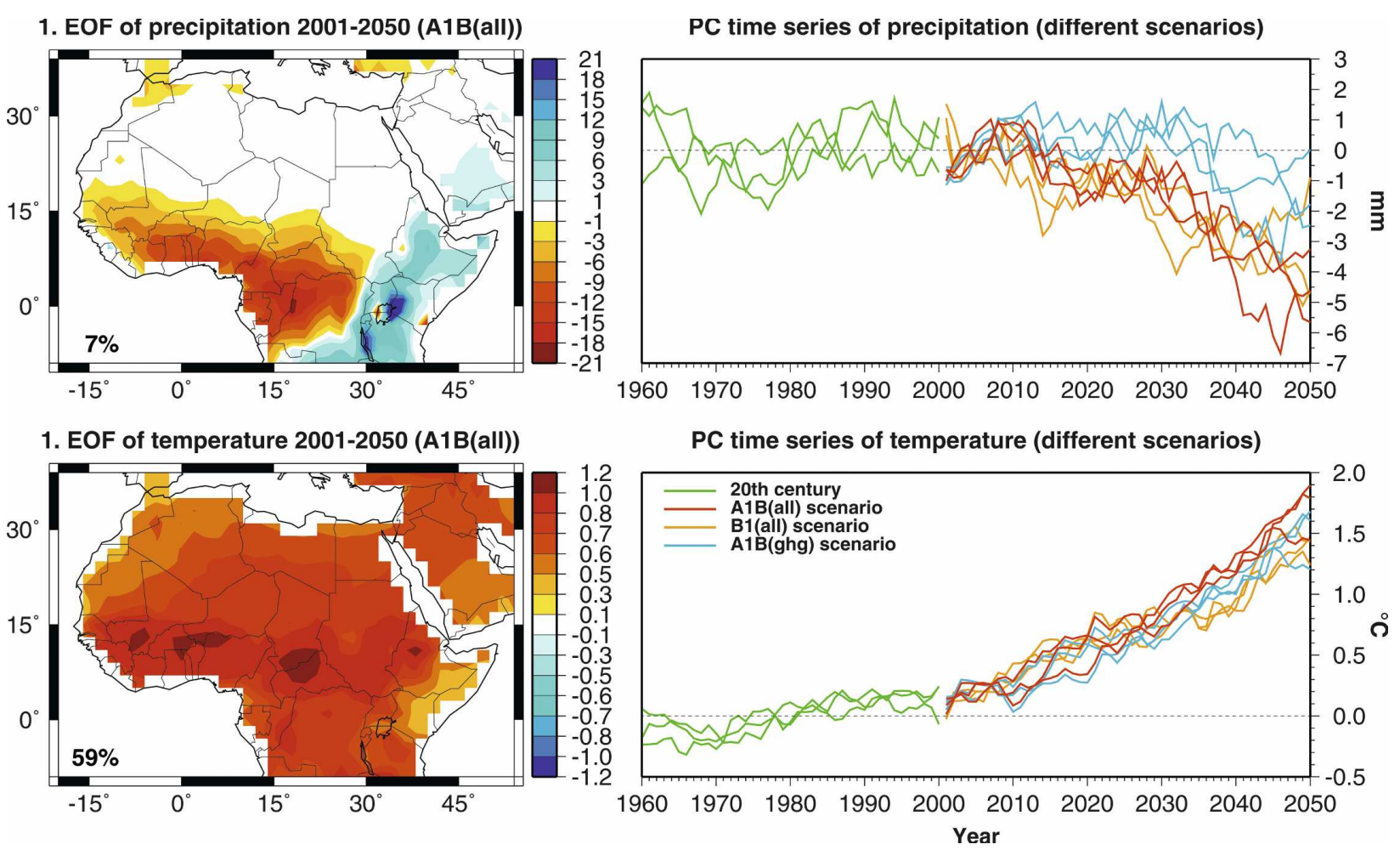

FIG. 8. Leading EOF patterns of monthly precipitation and near-surface temperature derived from the ensemble mean of the A1B(all) scenario runs during the period 2001-50. The PC time series are computed by projecting each single simulation of the twentieth century, $\mathrm{A} 1 \mathrm{~B}(\mathrm{all}), \mathrm{B} 1(\mathrm{all})$, and $\mathrm{A} 1 \mathrm{~B}(\mathrm{ghg})$ scenario onto these EOF patterns. The percentages indicate the explained variance of the respective EOF.

striking (59\% explained variance) than the EOF of precipitation $(7 \%)$. In general, rainfall is very noisy such that the long-term trend hardly stands out from the month-to-month variations. It is obvious that the warming and drying tendencies in tropical Africa prevail in the early twenty-first century when the land use changes are initiated in the model simulations. In contrast, the effect of GHG-only forcing on precipitation during the second half of the twentieth century is not statistically significant, although the principal component time series reflect the large-scale patterns of the leading EOFs. Until 2000, the time series are rather dominated by decadal variability with a slight warming tendency after 1970. It is obvious that the three scenarios-A1B(all), B1(all), and $\mathrm{A} 1 \mathrm{~B}$ (ghg) - all project onto the leading EOF pattern from $\mathrm{A} 1 \mathrm{~B}$ (all) and lead to the expected systematic differences: the warming rate is comparable between $\mathrm{B} 1$ (all) and $\mathrm{A} 1 \mathrm{~B}$ (ghg), but $0.6^{\circ} \mathrm{C}$ lower than in $\mathrm{A} 1 \mathrm{~B}($ all $)$ in the year 2050. The three scenarios start drifting apart from about 2035 onward. In terms of rainfall, $\mathrm{A} 1 \mathrm{~B}($ all) and $\mathrm{B} 1$ (all) are similar. However, compared with $\mathrm{A} 1 \mathrm{~B}(\mathrm{ghg})$ the consideration of land cover changes induces an acceleration of the precipitation response by almost $30 \mathrm{yr}$. The simu- lated trends in the principal components (PCs) can be regarded as a continuation of the observed long-term changes in sub-Saharan near-surface temperature and rainfall since the 1960s (Hulme et al. 2001; Nicholson 2001; Paeth and Hense 2004).

A logical consequence of the temperature increase in tropical Africa would be a modification of the largescale energy gradients, which in turn affect the monsoon circulation. Indeed, the summer monsoon flow into tropical western and central Africa intensifies (not shown). Although this effect is accompanied by an increasing moisture advection over sub-Sahelian Africa, it cannot compensate the drying trend induced by the damped local water recycling (cf. Paeth and Thamm 2007). Another circulation phenomenon over subSaharan Africa related to precipitation is the African easterly jet (AEJ) (see, e.g., Fink and Reiner 2003). The AEJ is a sometimes unstable flow in the lower troposphere $(700-500 \mathrm{hPa})$ that often switches to a wavelike structure: the African easterly waves (AEWs) initiated by orography or heat sources in the eastern Sahara. The AEWs are associated with deep convection and account for up to $80 \%$ of total annual rainfall amount in some regions of sub-Saharan Africa. A tem- 

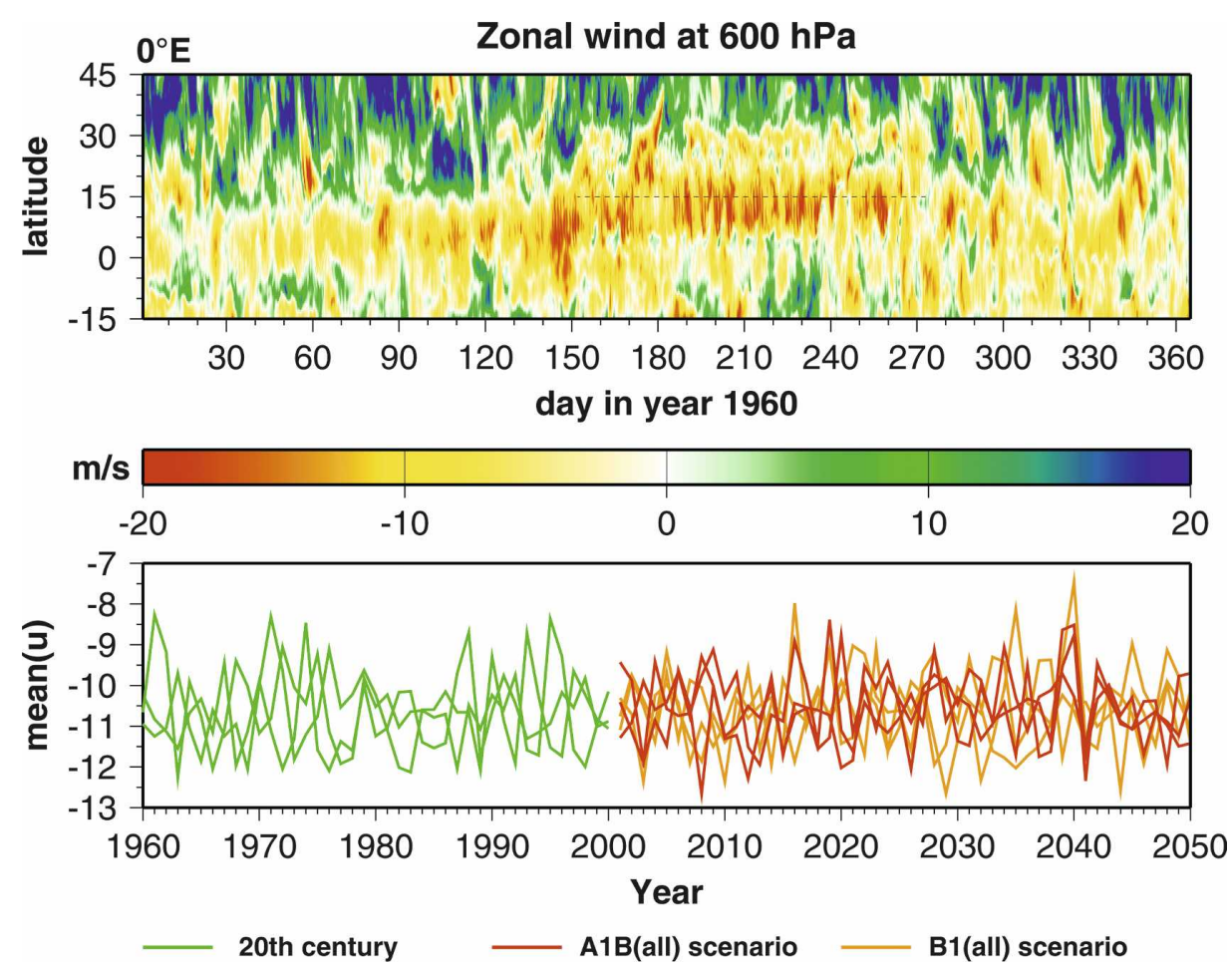

FIG. 9. (top) Hovmöller diagram of zonal wind velocity at $600 \mathrm{hPa}$ over West Africa depicted at $0^{\circ} \mathrm{E}$ during the year 1960. Positive (negative) values denote westerlies (easterlies). (bottom) Time series of the mean zonal wind in $600 \mathrm{hPa}$ at $15^{\circ} \mathrm{N}, 0^{\circ} \mathrm{E}$ over the June-September period (dashed line in top panel) of each year for different scenarios as an indicator of the African easterly jet.

perature increase with largest amplitude over tropical Africa should lead to a weakening of the AEJ and AEWs provided that the warming is barotropic up to the 600-hPa level. Figures 9 and 10 display the AEJ and AEWs in the form of Hovmöller diagrams of zonal and meridional wind at $600 \mathrm{hPa}$, respectively (cf. Paeth et al. 2005). The Hovmöller diagrams for the example year 1960 demonstrate the ability of REMO to simulate the AEJ and AEWs in the correct position and seasonal cycle with the AEWs propagating westward toward the tropical Atlantic at a time scale of around 6 days (cf. Paeth et al. 2005). The AEJ emerges in April and shifts northward to $15^{\circ} \mathrm{N}$ (Fig. 9). In late September it vanishes more or less abruptly. The index time series in the bottom panel of Fig. 9 refer to the mean zonal wind at $600 \mathrm{hPa}$ and $15^{\circ} \mathrm{N}, 0^{\circ} \mathrm{E}$ averaged over the JuneSeptember period. Neither the A1B(all) nor the B1(all) ensemble reveals a considerable change in the strength of the AEJ until 2050.

The AEWs occur during the June-September period (Fig. 10). The corresponding time series suggest a very slight tendency toward reduced wave activity, which would match the simulated drying trend in sub-Saharan Africa. However, the AEW changes do not stand out from the pronounced interannaul variations. It appears that the heating over tropical Africa is confined to the atmospheric boundary layer and barely affects the lower-tropospheric jet and wave dynamics. In general, the atmospheric circulation plays a minor role in the simulated temperature and precipitation changes over Africa, at least in this specific ECHAM5-REMO model-into-model approach. Assuming that it is not due to a deficient response of atmospheric circulation in ECHAM5/MPI-OM to radiative forcing, this finding demonstrates that the atmospheric response to land cover changes in REMO is not barotropic but is confined to the lower atmosphere.

\section{Changes in extreme climate}

It is evident that human societies and ecosystems in Africa are particularly sensitive to changes in climate extremes. However, the assessment of climate change signals in extreme values is not a simple task: simply because extreme events are rare by definition and, hence, are subject to sampling errors and model deficiencies (Meehl et al. 2000). We estimate extreme values of daily mean high temperature and of the length of dry spells during the summer monsoon season by fitting the generalized Pareto distribution to the model data 

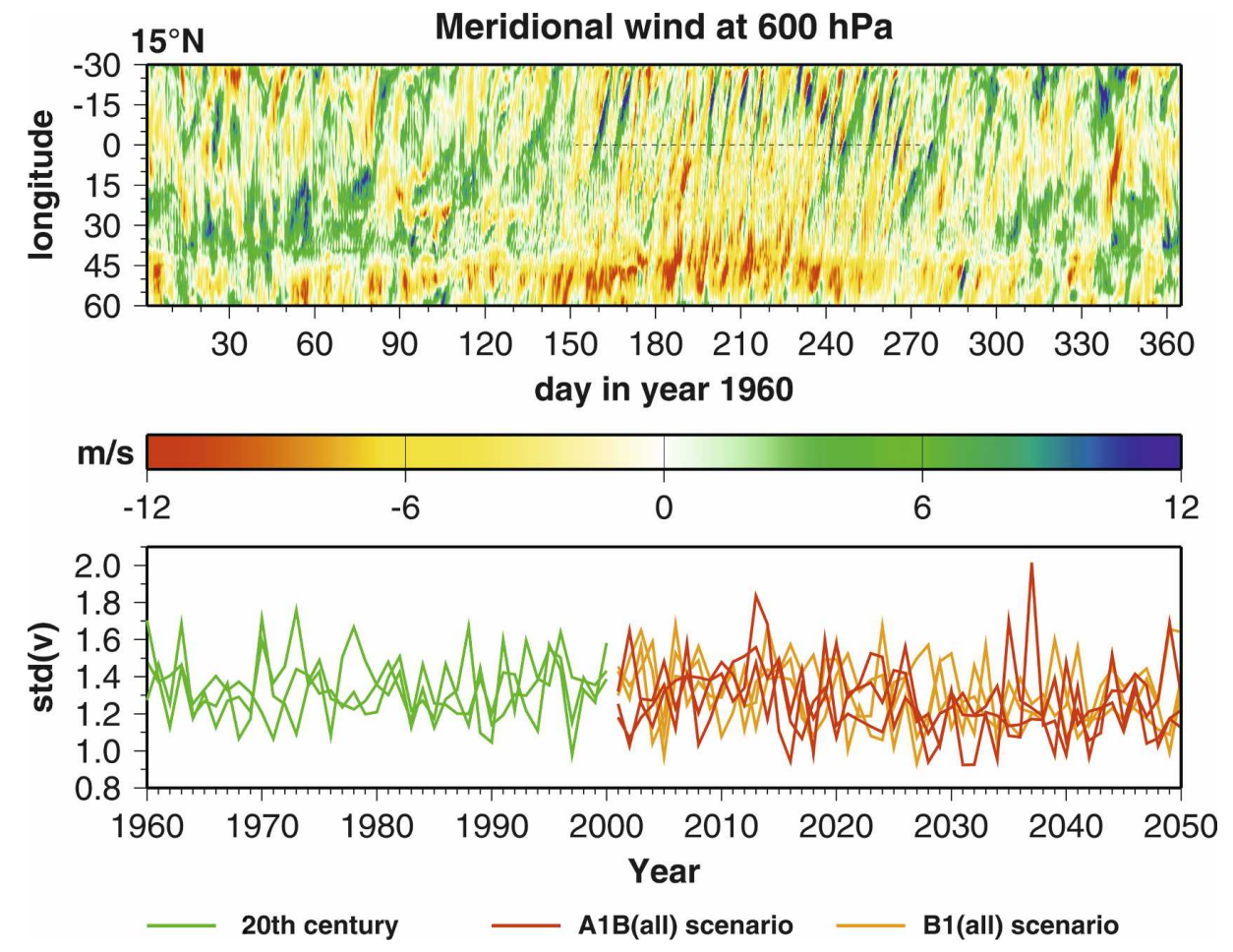

FIG. 10. As in Fig. 9 but for the meridional wind velocity depicted at $15^{\circ} \mathrm{N}$ and (bottom) as an indicator of the AEW. Positive (negative) values denote southerlies (northerlies).

(Paeth and Hense 2005). To reduce the influence of outliers and account for the relatively small sample sizes (90 values for the estimate of three parameters) the method of L moments is applied (Hosking 1990). The advantage of our approach is that the uncertainty range and statistical significance of the extreme value estimate and changes, respectively, can be assessed by a nonparametric Monte Carlo resampling approach and that return periods beyond the data period can be addressed (Kharin and Zwiers 2000; Paeth and Hense 2005). One hundred random samples are computed, and the confidence intervals of the extreme values are estimated. When two different subperiods in transient climate change experiments are compared with each other, changes in extreme values are defined to be statistically significant if the confidence intervals of both subperiods do not overlap (Kharin and Zwiers 2000).

Figure 11 (top) shows the 1-yr return values of extremely high daily mean temperature during the summer monsoon seasons from 1961 to 1970 in sub-Saharan Africa as a control case with relatively low human impact. The summer monsoon season has been chosen because it represents the main vegetation and agricultural period. The occurrence of heat days is a function of altitude and latitude. On average, the simulated warmest days during the June-September period occur in the western Sahel zone, amounting to more than $40^{\circ} \mathrm{C}$ locally. Along the Guinean Coast heat days do not exceed $30^{\circ} \mathrm{C}$. The effect of the East African highlands is also visible. Under the $\mathrm{A} 1 \mathrm{~B}$ (all) scenario, high temperature extremes may increase by up to $6^{\circ} \mathrm{C}$ until 2050 , which is almost twice as much as for the mean temperature (cf. Fig. 5). The B1(all) scenario leads to a similar pattern but with lower amplitude. Note that all plotted values are statistically significant at the $5 \%$ level. The intensification of heat days is directly related to a change in the Bowen ratio and reduced cloud cover during the summer monsoon season. Thus, the climate model experiments suggest that enhanced heat stress for humans may occur in sub-Saharan Africa.

A limiting factor for many agricultural crops in the low latitudes is related to the occurrence of dry spells during the rainy season. Many crops do not support monsoon breaks longer than 10 days to two weeks if no irrigation is undertaken (Webster et al. 1998). We define a dry spell as a number of consecutive days with simulated daily precipitation below $0.5 \mathrm{~mm}$. The $1-\mathrm{yr}$ return values of simulated extremely long dry spells during the 1961-70 West African summer monsoon are illustrated in Fig. 12 (top) for northern tropical Africa. There is a distinct meridional gradient ranging from a few days along the Guinean Coast to more than one 

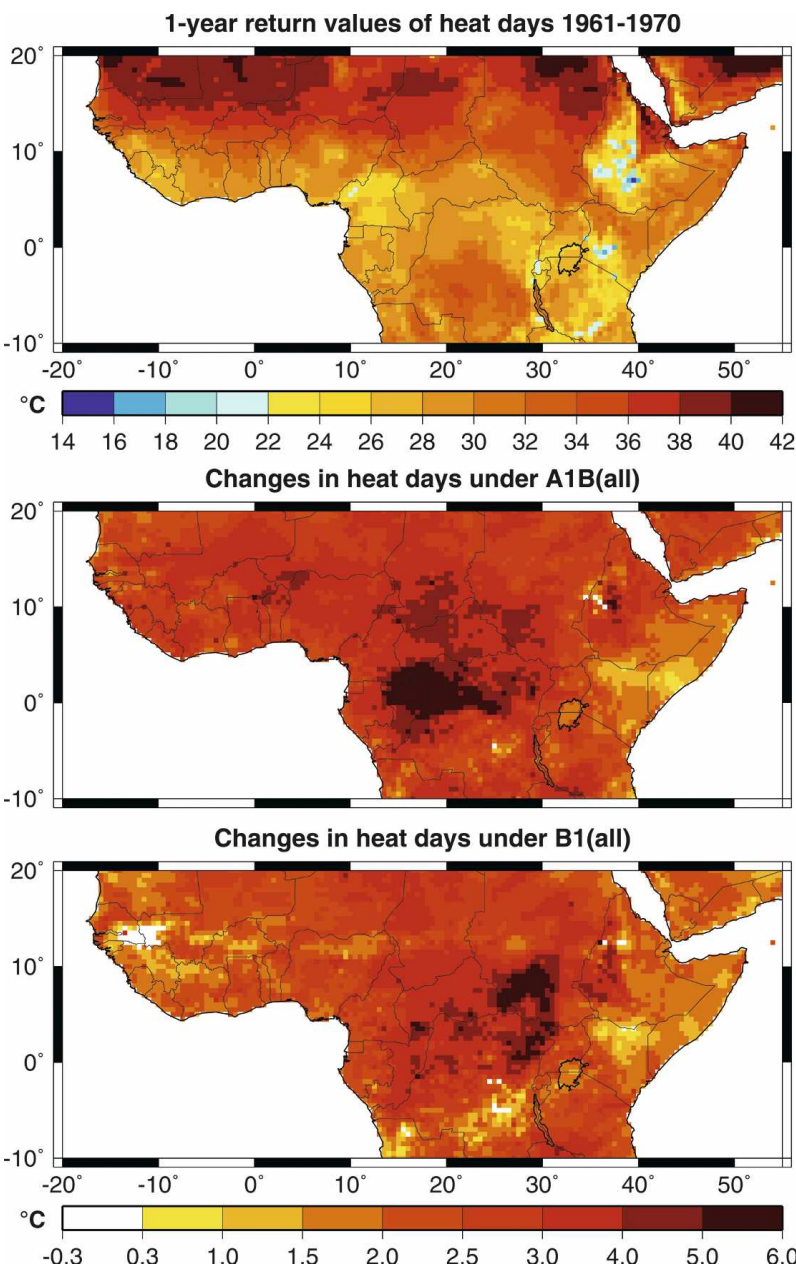

FIG. 11. One-year return values of warm daily temperature extremes during the July-September period in tropical Africa: (top) climatology during the 1961-70 period; (middle) changes between the last (2041-50) and the first (1961-70) decade of the model period under the A1B(all) scenario; (bottom) changes between the last and the first decade of the model period under the B1(all) scenario. Only changes statistically significant at the $5 \%$ level are plotted.

month in the southern Sahel zone. A natural boundary of agriculture without irrigation can be drawn at $\sim 12^{\circ} \mathrm{N}$. Under the A1B(all) scenario, the dry spells become substantially longer over most of tropical West Africa (Fig. 12, middle). Again, A1B(all) and B1(all) scenarios do not show up with noticeable differences in terms of projected changes in the hydrological cycle (cf. Figs. 6 and 8). The patterns of statistically significant changes are rather coherent in space, which is not selfevident for changes in rainfall extremes (cf. Meehl et al. 2000; Paeth and Hense 2005; Paeth and Thamm 2007). Given a threshold of 10-14 days for agriculture without irrigation, this tendency may have large implications for future food supply in these regions.
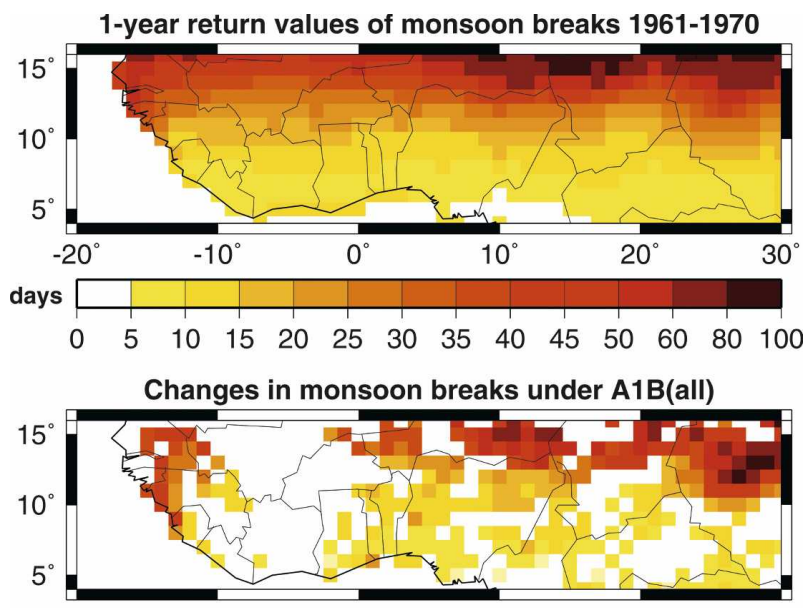

Changes in monsoon breaks under B1(all)

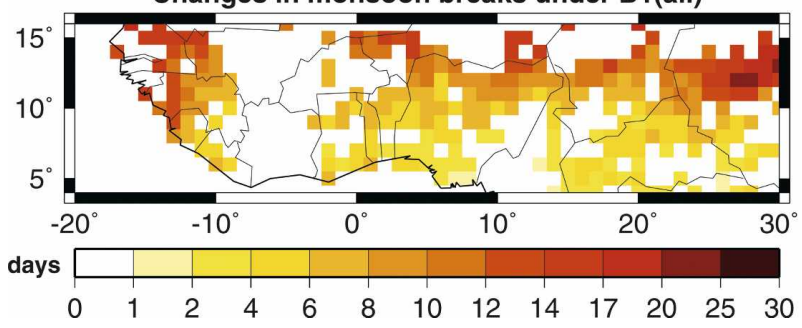

FIG. 12. As in Fig. 11 but for extreme dry spells during the May-October rainy season in northern tropical Africa

Note that the absolute values in Figs. 11 and 12 should be interpreted with care given the deficiency of climate models, in general, to simulate climate extremes (Meehl et al. 2000; Zolina et al. 2004). Under the assumption that this model bias is systematic, the difference patterns in Figs. 11 and 12 are likely to be more reliable.

\section{Signal analysis}

Finally, the question arises whether the land use changes plus greenhouse forcing stand out from internal variability at the scale of $0.5^{\circ} \times 0.5^{\circ}$ grid boxes in REMO or whether this regional scale is rather characterized by spatial noise as imposed by the varied initial conditions of the ensemble members. This generally enhances the utility of a regional model in supporting political decisions at the regional and national scale. The issue can be quantified by a two-way analysis of variance (von Storch and Zwiers 1999; Paeth and Feichter 2006). Given two (or more) ensembles from the same climate model with different forcings [here $\mathrm{A} 1 \mathrm{~B}($ all) versus B1(all)], the total variance of the data can be decomposed into four sums of squares:

$$
\mathrm{SS}_{t}=\mathrm{SS}_{\alpha}+\mathrm{SS}_{\beta}+\mathrm{SS}_{\gamma}+\mathrm{SS}_{\epsilon} \text {. }
$$




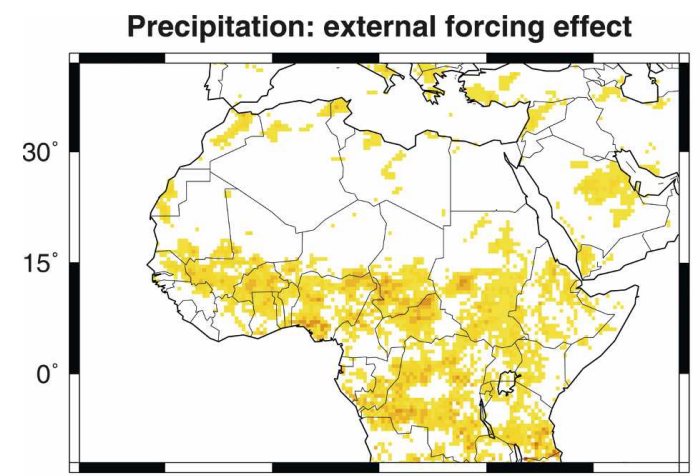

Temperature: external forcing effect

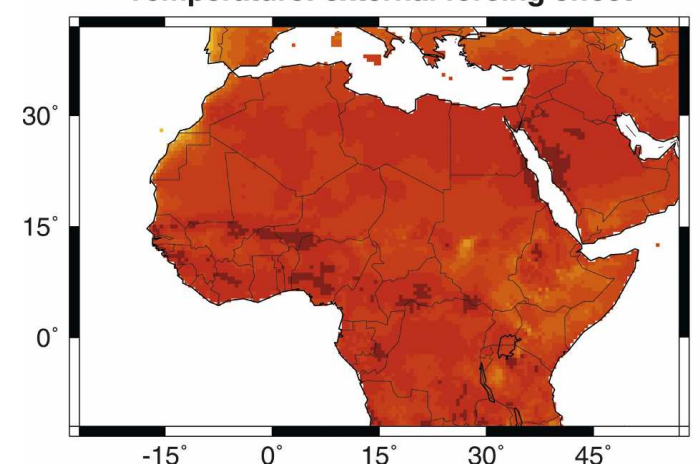

Precipitation: A1B(all) versus B1(all) effect

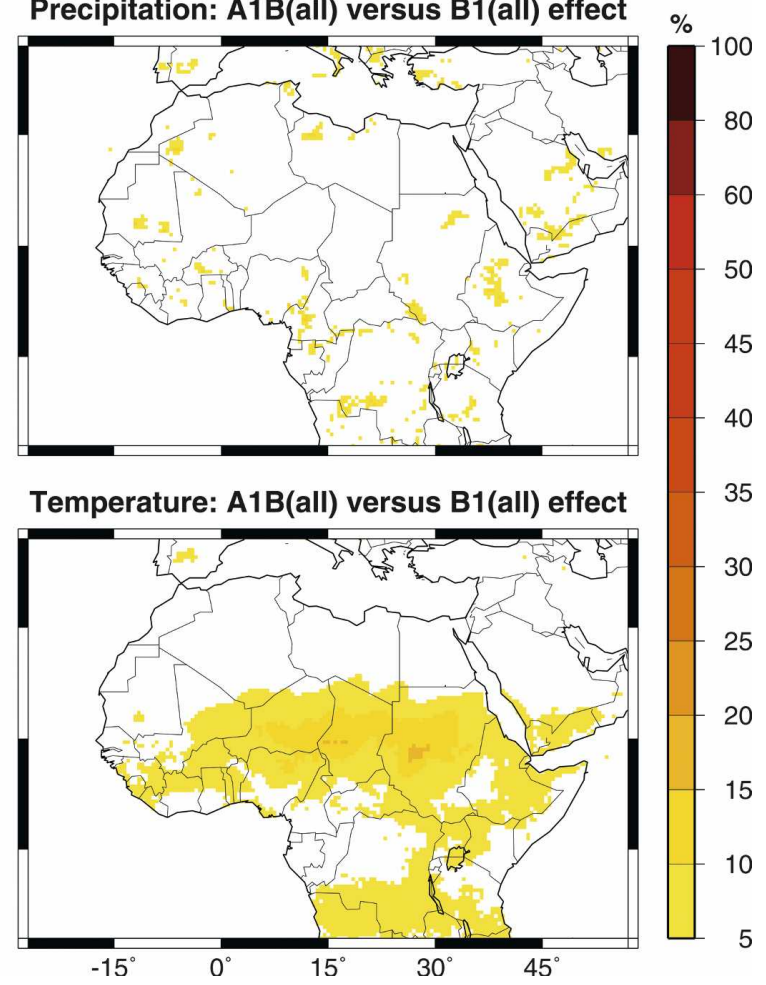

FIG. 13. Results of the two-way analysis of variance: (left) portion of the total year-to-year variability of annual (top) precipitation and (bottom) near-surface temperature over land explained by greenhouse warming plus land use changes, common to scenarios A1B(all) and B1(all); (right) effect of different forcings, A1B(all) vs B1(all), in percentage of total year-to-year variability. Only values statistically significant at the $5 \%$ level are plotted. For explanations see text.

1) The so-called block effect $\mathrm{SS}_{\alpha}$ denotes the timeindependent systematic difference between the ensemble means $[\mathrm{A} 1 \mathrm{~B}($ all) versus $\mathrm{B} 1($ all $)]$. In our case this effect is small because both ensembles have been realized with the same regional climate model. 2) The so-called treatment effect $\mathrm{SS}_{\beta}$ reflects the variance of the multiensemble mean series, averaged over the $\mathrm{A} 1 \mathrm{~B}($ all) and B1(all) ensembles. It is a measure of the overall external human forcing (in our case by greenhouse gases and land degradation) common to the $\mathrm{A} 1 \mathrm{~B}(\mathrm{all})$ and $\mathrm{B} 1$ (all) ensembles and, hence, denotes the sought-after climate change signal. 3) The so-called interaction coefficient $\mathrm{SS}_{\gamma}$ describes the time-dependent systematic difference between both ensemble means. It is large if the temporal evolution of the ensemble means is different between the $\mathrm{A} 1 \mathrm{~B}$ (all) and B1(all) ensemble (as, e.g., indicated in Fig. 8). Here the interaction coefficient indicates the effect of different amounts of GHG emissions and land use changes according to our combined scenarios, $\mathrm{A} 1 \mathrm{~B}($ all) and $\mathrm{B} 1$ (all), and, thus, can be interpreted as the mitigation of future climate change according to a more climateoriented policy under the B1(all) scenario. 4) The remaining portion of total variability marks the internal variability $\mathrm{SS}_{\epsilon}$, which arises from the randomly chosen initial conditions of the individual ensemble members. This so-called residual cannot be explained either by the block and treatment effects or by their interaction.

Figure 13 displays the contribution of the treatment effect, which marks the external anthropogenic forcing (left panels), and the interaction coefficient, which stands for the efficiency of mitigation policy (right panels), to total interannual variability of near-surface temperature and precipitation at individual grid boxes during the 2001-50 period. Land use changes and greenhouse forcing account for up to $80 \%$ of the year-to-year temperature variations and, hence, represent a prominent climate change signal, particularly in sub-Saharan Africa. Although interannual rainfall variability is mainly governed by stochastic fluctuations, a statistically significant and spatially coherent signal emerges over most of tropical Africa. Thus, the impact of land use changes and GHG-induced radiative heating prevails even at the level of individual grid boxes. However, it has to be taken into account that ECHAM5 and REMO, like most other climate models, underestimate the amount of internal variability (see section 3 ). The B1(all) mitigation scenario implies a significantly 
weaker near-surface warming compared with the A1B(all) business-as-usual scenario, whereas no significant effect is found for the drying trend, that is, unless the land use changes are completely switched off in the A1B(ghg) ensemble (cf. Fig. 6). As shown before, $\mathrm{A} 1 \mathrm{~B}($ all) and B1(all) are quite consistent in causing a dramatic weakening of the hydrological cycle over most of sub-Saharan Africa (cf. Figs. 6, 8, and 12). Of course, this finding has to be confirmed by other models as it is of major relevance for climate policy in Africa: The mitigation of land degradation at the regional scale may be more important for maintaining the water cycle than the reduction of GHG emissions at the global scale.

\section{Conclusions}

Ensemble simulations with the regional climate model REMO have been realized under various scenario assumptions in order to compare the impact of land cover changes and GHG forcing in the light of future regional climate change over northern and central Africa. A stochastic model has been developed to estimate the patterns of future land cover changes in tropical and northern Africa until 2050. Combined with increasing GHG concentrations according to the IPCC scenarios $\mathrm{A} 1 \mathrm{~B}$ and $\mathrm{B} 1$, this experimental design is supposed to account for the human impact on climate more realistically than the more classical view with greenhouse (and aerosol) forcing only.

In this model study, basic characteristics of African climate as observed during the second half of the twentieth century could be reproduced to be fairly realistic. The ensemble runs with combined GHG and land cover scenarios project a warmer and drier climate until the middle of the twenty-first century. In our specific ECHAM5-REMO downscaling experiments, the spatial pattern and the amplitude of the precipitation changes are mainly governed by land degradation, whereas greenhouse forcing and land cover changes are equally important for the near-surface warming. Land degradation accelerates the negative rainfall trend by almost $30 \mathrm{yr}$, compared with the GHG-only forcing. The midtropospheric circulation phenomena over West Africa, that is, AEJ and AEWs, are realistically simulated by REMO but appear to be less sensitive to the imposed radiative forcing and land cover changes, except for a slight weakening of AEW activity. This implies that land degradation has a rather local effect on near-surface climate that is sufficient to damp the hydrological cycle but does not dramatically feed back on the large-scale energy gradients in the West African monsoon region. There are statistically significant changes in some climate extremes as well: Heat days seem to intensify, and even more dramatic is the extension of monsoon breaks in large areas of the West African monsoon region. This process implies a further narrowing of the natural borders of agriculture in subSaharan Africa if irrigation is applied (cf. Webster et al. 1998). The decomposition of total temperature and rainfall variability highlights the statistically significant external control of future African climate owing to greenhouse forcing and, particularly, land degradation. As to be expected, the temperature signal is more apparent than the precipitation signal because the latter is more noisy in time and space. Assuming sufficient reliability of the model results, the two-way analysis of variance also indicates that the mitigation policy as accounted for in the IPCC B1 scenario may not have a major impact on the negative precipitation trend over sub-Saharan Africa unless the land cover changes are switched off.

These results obtained from our regional climate model with presumably realistic forcing conditions draw a rather pessimistic picture of future African climate. In addition to the current problems of economic underdevelopment and high population growth, the increase in dry spells and heat stress may further harm agriculture and food supply in sub-Saharan Africa (cf. Challinor et al. 2007). Nonetheless, the mitigation policy that protects the landscape will benefit Africans greatly. Such a policy could include measures like controlled agriculture and settlement as well as protection areas for natural forests. Reforestation would be another option, which additionally represents a more or less efficient carbon sink (Jackson et al. 2005).

Given the large discrepancies between present-day global climate model predictions for Africa (Paeth et al. 2008; Solomon et al. 2007), one still has to scrutinize whether other global and regional climate models will corroborate our findings under comparable forcing conditions. In particular, one needs to investigate to what extent the weak response of REMO precipitation to the greenhouse forcing arises from a potential caveat of the ECHAM5/MPI-OM global climate model. When the land use changes are not accounted for in our regional climate model, there is some basic agreement with present-day global climate model simulations with greenhouse forcing only, that is, a northward shift of the precipitation maximum into the Sahel zone (Hulme et al. 2001; Coppola and Giorgi 2005; Kamga et al. 2005; Hoerling et al. 2006). However, we find a completely different precipitation trend under the combined forcing that is more consistent with the observed tendency since the 1960s (Nicholson 2001; Lu and Delworth 2005).

The next challenge is to implement further compo- 
nents in the scenario setup, including the effect of atmospheric aerosols, for example, from biomass burning in Africa, which may further weaken the hydrological cycle (Paeth and Feichter 2006) and alter the warming rate (Caminade and Terray 2006), as well as the effect of fully interactive vegetation cover with the vegetation directly reacting on dry spells and heat stress. The latter is also supposed to enhance the amplitude of the rainfall decrease due to a positive feedback. In addition, interactive vegetation may increase interannual variability up to the observed level. Another important task is to assess the probable range of land cover change scenarios for Africa in a more sophisticated way, that is, by using socioeconomic, demographic, and technologic factors. However, the most important task is to evaluate our results with other global and regional climate models in order to ensure that the prominent climate change signals are robust in the light of different model physics.

Acknowledgments. This work was supported by the Federal German Minister of Education and Research (BMBF) under Grant 07 GWK 02 and by the Ministry of Education, Science and Research (MSWF) of the Federal State of Northrhine-Westfalia under Grant 223-21200200. We thank our colleagues from the German interdisciplinary IMPETUS project for providing data and material and for helpful discussions.

\section{REFERENCES}

Benson, C., and E. J. Clay, 1998: The impact of drought on subSaharan African economies: A preliminary examination. World Bank Tech. Paper 401, World Bank Publications, 80 pp.

Caminade, C., and L. Terray, 2006: Influence of increased greenhouse gases and sulphate aerosols concentration upon diurnal temperature range over Africa at the end of the 20th century. Geophys. Res. Lett., 33, L15703, doi:10.1029/ 2006 GL026381.

Challinor, A., T. Wheller, C. Garforth, P. Craufurd, and A. Kassam, 2007: Assessing the vulnerability of food crop systems in Africa to climate change. Climatic Change, 83, 381-399.

Charney, J., 1975: Dynamics of deserts and drought in the Sahel. Quart. J. Roy. Meteor. Soc., 101, 193-202.

Cook, K. H., and E. K. Vizy, 2006: Coupled model simulations of the West African monsoon system: Twentieth- and twentyfirst-century simulations. J. Climate, 19, 3681-3703.

Coppola, E., and F. Giorgi, 2005: Climate change in tropical regions from high-resolution time-slice AGCM experiments. Quart. J. Roy. Meteor. Soc., 131, 3123-3145.

de Wit, M., and J. Stankiewicz, 2006: Changes in surface water supply across Africa with predicted climate change. Science, 311, 1917-1921.

Douville, H., S. Planton, J.-F. Royer, D. B. Stephenson, S. Tyteca, L. Kergoat, S. Lafont, and R. A. Betts, 2000: Importance of vegetation feedbacks in doubled- $\mathrm{CO}_{2}$ climate experiments. $J$. Geophys. Res., 105, 14 841-14 861.

Eklundh, L., and L. Olsson, 2003: Vegetation index trends for the
African Sahel 1982-1999. Geophys. Res. Lett., 30, 1430, doi:10.1029/2002GL016772.

Eltahir, E. A. B., 1996: The role of vegetation in sustaining largescale atmospheric circulations in the tropics. J. Geophys. Res., 101, 4255-4268.

— sphere to large-scale deforestation. Quart. J. Roy. Meteor. Soc., 119, 779-793.

FAO, 2006: Global forest resources assessment 2005: Progress towards sustainable forest management. Food and Agriculture Organization Forestry Paper 147, 348 pp.

Feddema, J. J., and S. Freire, 2001: Soil degradation, global warming and climate impacts. Climate Res., 17, 209-216.

-, K. W. Oleson, G. B. Bonan, L. O. Mearns, L. E. Buja, G. A. Meehl, and W. M. Washington, 2005: The importance of land-cover change in simulating future climates. Science, $\mathbf{3 1 0}$, 1674-1678.

Findley, S. E., 1994: Does drought increase migration? A study of migration from rural Mali during the 1983-1985 drought. Int. Migr. Rev., 28, 539-553.

Fink, A. H., and A. Reiner, 2003: Spatiotemporal variability of the relation between African Easterly Waves and West African squall lines in 1998 and 1999. J. Geophys. Res., 108, 4332, doi:10.1029/2002JD002816.

Giorgi, F., 2006: Climate change hot-spots. Geophys. Res. Lett., 33, L08707, doi:10.1029/2006GL025734.

Hagemann, S., 2002: An improved land-surface parameter data set for global and regional climate models. MPI Rep. 336, 21 pp.

—, M. Botzet, L. Dumenil, and B. Machenhauer, 1999: Derivation of global GCM boundary conditions from $1 \mathrm{~km}$ land use satellite data. MPI Rep. 289, 34 pp.

Hoerling, M. P., J. W. Hurrell, J. Eischeid, and A. Phillips, 2006: Detection and attribution of 20th century northern and southern African rainfall change. J. Climate, 19, 3989-4008.

Hosking, J. R. M., 1990: L-moments: Analysis and estimation of distributions using linear combinations of order statistics. $J$. Roy. Stat. Soc. Ser. A, B52, 105-124.

Hulme, M., R. Doherty, T. Ngara, M. New, and D. Lister, 2001: African climate change: 1900-2100. Climate Res., 17, 145-168.

Jackson, R. B., and Coauthors, 2005: Trading water for carbon with biological carbon sequestration. Science, 310, 1944-1947.

Jacob, D., and Coauthors, 2001: A comprehensive model intercomparison study investigating the water budget during the PIDCAP period. Meteor. Atmos. Phys., 77, 19-44.

— , and Coauthors, 2007: An inter-comparison of regional climate models for Europe: Model performance in present-day climate. Climatic Change, 81, 31-52.

Jenkins, G. S., A. Kamga, A. Garba, A. Diedhiou, V. Morris, and E. Joseph, 2002: Investigating the West African climate system using global/regional climate models. Bull. Amer. Meteor. Soc., 83, 583-595.

Kamga, A. F., G. S. Jenkins, A. T. Gaye, A. Garba, A. Sarr, and A. Adedoyin, 2005: Evaluating the National Center for Atmospheric Research climate system model over West Africa: Present-day and the 21st century A1 scenario. J. Geophys. Res., 110, D03106, doi:10.1029/2004JD004689.

Kharin, V. V., and F. W. Zwiers, 2000: Changes in extremes in an ensemble of transient climate simulations with a coupled atmosphere-ocean GCM. J. Climate, 13, 3760-3788.

Knorr, W., and K.-G. Schnitzler, 2006: Enhanced albedo feedback in North Africa from possible combined vegetation and soil formation processes. Climate Dyn., 26, 55-63.

Lamptey, B. L., E. J. Barron, and D. Pollard, 2005: Simulation of 
the relative impact of land cover and carbon dioxide to climate change from 1700 to 2100. J. Geophys. Res., 110, D20103, doi:10.1029/2005JD005916.

Lotsch, A., M. A. Friedl, and B. T. Anderson, 2003: Coupled vegetation-precipitation variability observed from satellite and climate records. Geophys. Res. Lett., 30, 1774, doi:10.1029/ 2003GL017506.

Lu, J., and T. L. Delworth, 2005: Oceanic forcing of the late 20th century Sahel drought. Geophys. Res. Lett., 32, L22706, doi:10.1029/2005GL023316.

Maynard, K., and J.-F. Royer, 2004: Effects of "realistic" landcover change on a greenhouse-warmed African climate. Climate Dyn., 22, 343-358.

Meehl, G. A., F. Zwiers, J. Evans, T. Knutson, L. Mearns, and P. Whetton, 2000: Trends in extreme weather and climate events: Issues related to modeling extremes in projections of future climate change. Bull. Amer. Meteor. Soc., 81, 427-436.

Nakicenovic, N., and R. Swart, Eds., 2000: Emission Scenarios. Cambridge University Press, $570 \mathrm{pp}$.

New, M., M. Hulme, and P. Jones, 2000: Representing twentiethcentury space-time climate variability. Part II: Development of 1901-96 monthly grids of terrestrial surface climate. J. Climate, 13, 2217-2238.

Nicholson, S. E., 2001: Climatic and enviromental change in Africa during the last two centuries. Climate Res., 17, 123-144.

Oertel, D., B. Zhukov, H.-P. Thamm, J. Roehrig, and B. Orthmann, 2004: Space-borne high resolution fire remote sensing in Benin, West Africa. Int. J. Remote Sens., 25, 2209-2216.

Paeth, H., 2004: Key factors in African climate change evaluated by a regional climate model. Erdkunde, 58, 290-315.

— West African rainfall: 20 th century variations and future projections. Climatic Change, 65, 179-208.

— , and J. Stuck, 2004: The West African dipole in rainfall and its forcing mechanisms in global and regional climate models. Mausam, 55, 561-582.

— Mediterranean region and its sensitivity to future global warming conditions. Meteor. Z., 14, 329-347.

— and African climate response. Climate Dyn., 26, 35-54.

— , and A. Hense, 2006: On the linear response of tropical African climate to SST changes deduced from regional climate model simulations. Theor. Appl. Climatol., 83, 1-19.

— rican climate north of $15^{\circ} \mathrm{S}$ including greenhouse warming and land degradation. Climatic Change, 83, 401-427.

-, K. Born, R. Podzun, and D. Jacob, 2005: Regional dynamic downscaling over West Africa: Model evaluation and comparison of wet and dry years. Meteor. Z., 14, 349-367.

— A. Scholten, P. Friederichs, and A. Hense, 2008: Uncertainties in climate change prediction: El Niño-Southern Oscillation and monsoons. Global Planet. Change, 60, 265-288.

Pielke, R. A., Sr., 2001: Influence of the spatial distribution of vegetation and soils on the prediction of cumulus convective rainfall. Rev. Geophys., 39, 151-177.

- , and Coauthors, 2002: The influence of land-use change and landscape dynamics on the climate system: Relevance to climate-change policy beyond the radiative effect of greenhouse gases. Philos. Trans. Roy. Soc. London, 360A, 1705-1719.

Roeckner, E., and Coauthors, 2003: The atmospheric general cir- culation model ECHAM 5. PART I: Model description. MPI Rep. 349, 127 pp.

Saha, K. R., and S. Saha, 2001: African monsoons. Part 1: Climatological structure and circulation. Mausam, 52, 479-510.

Schnitzler, K.-G., W. Knorr, M. Latif, J. Bader, and N. Zeng, 2001: Vegetation feedback on Sahelian rainfall variability in a coupled climate land-vegetation model. MPI Rep. 329, 13 pp.

Semazzi, F. H. M., and Y. Song, 2001: A GCM study of climate change induced by deforestation in Africa. Climate Res., 17, 169-182.

Solomon, S., D. Qin, M. Manning, Z. Chen, M. Marquis, K. B. Averyt, M. Tignor, and H. L. Miller, Eds., 2007: Climate Change 2007: The Physical Science Basis. Cambridge University Press, 996 pp.

Taylor, C. M., E. F. Lambin, N. Stephenne, R. J. Harding, and R. L. H. Essery, 2002: The influence of land-use change on climate in the Sahel. J. Climate, 15, 3615-3629.

Texier, D., N. de Noblet, and P. Braconnot, 2000: Sensitivity of the African and Asian monsoons to mid-Holocene insolation and data-inferred surface changes. J. Climate, 13, 164-181.

Thamm, H.-P., M. Judex, and G. Menz, 2005: Modelling of landuse and land-cover change (LUCC) in western Africa using remote-sensing. Photogramm. Fernerkundung Geo-inf., H3, 191-199.

UN, 2006: World population prospects: The 2004 revision. Department of Economic and Social Affairs, United Nations Publications, 105 pp. [Available online at http://www.un.org/ esa/population/publications/WPP2004/2004Highlights_finalrevised.pdf.]

von Storch, H., and F. W. Zwiers, 1999: Statistical Analysis in Climate Research. Cambridge University Press, 484 pp.

Wang, G., and E. A. B. Eltahir, 2000: Ecosystem dynamics and the Sahel drought. Geophys. Res. Lett., 27, 795-798.

, — - J. A. Foley, D. Pollard, and S. Levis, 2004: Decadal variability of rainfall in the Sahel: Results from the coupled GENESIS-IBIS atmosphere-biosphere model. Climate Dyn., 22, 625-637.

Webster, P. J., V. O. Magaña, T. N. Palmer, J. Shukla, R. A. Tomas, M. Yanai, and T. Yasunari, 1998: Monsoons: Processes, predictability and the prospects for prediction. J. Geophys. Res., 103, 14 451-14 510.

Werth, D., and R. Avissar, 2005: The local and global effects of African deforestation. Geophys. Res. Lett., 32, L12704, doi:10.1029/2005GL022969.

Worden, J., D. Noone, K. Bowman, and The Tropospheric Emission Spectrometer Science Team and Data Distributors, 2007: Importance of rain evaporation and continental convection in the tropical water cycle. Nature, 445, 528-532.

Zeng, N., and J. D. Neelin, 2000: The role of vegetation-climate interaction and interannual variability in shaping the African Savanna. J. Climate, 13, 2665-2670.

_, K. Hales, and J. D. Neelin, 2002: Nonlinear dynamics in a coupled vegetation-atmosphere system and implications for desert-forest gradient. J. Climate, 15, 3474-3487.

Zhao, M., and A. J. Pitman, 2002: The impact of land cover change and increasing carbon dioxide on the extreme and frequency of maximum temperature and convective precipitation. Geophys. Res. Lett., 29, 1078, doi:10.1029/2001GL013476.

Zolina, O., A. Kapala, C. Simmer, and S. Gulev, 2004: Analysis of extreme precipitation over Europe from different reanalyses: A comparative assessment. Global Planet. Change, 44, 129-161. 